\title{
PREDICTION OF FUTURE EXPECTED DAMAGE OF UNDERGROUND R.C. ELEMENTS EXPOSED TO INDUCED SEWAGE WATER THROUGH UNCONFINED POROUS MEDIA
}

\section{Rashwan M. M.}

Associate professor, Civil Engineering Department, Assiut University, Assiut, Egypt.

(Received May 15, 2006, Accepted June 17, 2006)

Sulfate and chloride attack for underground R.C. constructions is an important subject of many researchers. Chemical attack by aggressive waters specially sewage is one of the factors causing deterioration and corrosion damage of concrete in the underground R.C. elements. The chemical resistance of R.C. elements against chloride and sulfate attack induced by sewage water is expressed by the percentage of their mechanical property losses. Sulfate attack of concrete building foundations induced by sewage water was studied in the field. Effect of the diffused salts concentration by sewage waters from multiple seepage pits through a confined porous media on the load carrying capacity of underground R.C. columns was analytically studied. But, the influence of chloride and sodium sulfate solutions diffused by sewage water through unconfined porous media on the expected deterioration and corrosion damage of underground R.C. elements after a long period of time, specially footings and necks of columns, has not been enough studied.

So, in this paper is developed an analytic model for the effect of the induced chloride and sodium sulfate salts by sewage water through unconfined porous media on the future corrosion damage and deterioration of concrete in underground R.C. elements specially columns. The finite difference technique is used and a computer program is developed and written in a basic language to compute the future mechanical properties losses of R.C. elements exposed to sewage water for a long period of time.

Analysis of the numerical results shows that, the expected deterioration and corrosion damage of any underground R.C. elements exposed to sodium sulfate and chloride solutions flow induced by sewage water depend mainly on the time of exposure to these salts, radial distance of the concrete structure from the sewage resources and their number, height of the sewage water solution and its relative concentration at that structure. The difference between the values of of " $C F c$ " and " $C c_{f}$ " for unconfined and confined porous media decreases gradually and slowly with increasing time until reaching equal value $\left(C F c=0.696, \epsilon c_{f}=5.48 \times 10^{-4}\right)$ after 8 years. The unconfined porous media properties $(k, \phi)$ and total relative concentration "Ca/Co" of diffused chloride and sulfate salts at that structure have not any effect on its mechanical properties losses. 
KEYWORD: deterioration, corrosion damage, sewage water, unconfined porous media, chloride and sodium sulfate attack, underground, dispersion, solution, analytic model, correction factor, porosity, permeability, compressive strength, yield stress, strain.

\section{INTRODUCTION}

Sulfate and chloride attack for underground R.C. constructions is an important subject of many researchers. Chemical attack by aggressive waters, especially sewage, is one of the factors causing damage to the used concrete in underground R.C. elements. Concrete can be deteriorated in many ways. One of the typical deterioration is caused by the corrosion of reinforcing steel and subsequent spalling of the concrete cover [1]. The use of seepage pits or deep wells for the disposal of partially treated sewage waters and waste products through confined or unconfined porous media are important aspects for sewage water disposal planning. These seepage pits are recognized as the chloride and sulfate sources due to the microorganism metabolism of sulfur and chloride compounds present in sewage. Consequences of this attack were a very poor bond strength between cement paste and aggregates, which reduce compressive strength of concrete, a severe cracking of the concrete cover around steel reinforcement and corrosion damage of embedded reinforcement. The degradation effects increase with decreasing the distance of R.C. structures from these seepage pits or absorbing wells located in courtyard of the building [2].

The chemical resistance of R.C. elements against chloride and sulfate attack induced by sewage water is expressed by the percentage of their mechanical property losses. These losses are the reduction of concrete compressive strength and steel yield stress, increase of concrete strain and corrosion rate of steel with time compared with similar concrete not exposed to sewage waters. [2,3]. Sulfate attack of concrete building foundations induced by sewage water was studied by Negro and Mario Collepardi [2]. They concluded that, the degration of effects increased with decreasing the distance of concrete structures from an absorbing well located in the courtyard of the building.

Some experimental studies were carried out to show the effect of sulfate attack on the damage of R.C. element [3]. Deterioration of concrete by sulfuric acid produced from sewage is a long term process, but, poor quality concrete deteriorates at a much faster rate than good-quality ones [4]. In addition, when a sulfuric attack is active, under a very low " $\mathrm{pH}$ ", all hydrated products, hydrated silicate and aluminate phases and calcium hydroxide can easily be decomposed, leading to a severe disintegration of the concrete matrix [5]. In fact, as previously stated [2,6], the etteringite expansion phenomenon is in adequate to explain the sulfate-generated deterioration of the concrete. Also, the ferrous chloride phenomenon in the presence of oxygen is in adequate to explain the generated corrosion damage of embedded steel bars.

Manu Santhanam, Menashi D. Cohen [7] investigated the effects of different concentrations of sodium and magnesium sulfate solutions on expansion and microstructure of different types of Portland cement mortars. They indicated that, the 
ultimate of failure of the specimen occurs as a result of the decalcification of the calcium silicate hydrate (C-S-H), and its conversion to magnesium silicate hydrate (M-S-H), after prolonged exposure to the solution.

Adam Neville [8] studied the mechanisms of attack on concrete by different sulfates-sodium, calcium and magnesium including the issue of topochemical and through solution reactions including the effect of soil properties.

The concentration of chloride and sulfate salt solutions in wastewater's disposal, through unconfined porous media, is transported from the sewage source to any point in their flow in a radial direction depending on the coefficient of transmissibility of the porous media. Field studies on dispersion of pollution recharged by wells have been performed by many authors $[9,10,11]$. In their work, the chemical constituents in wastewater were transported with recharged water far from the well while miscible was restrained and accumulated in voids of soil particles near the well.

The problem of unsteady radial flow to a well penetrating an unconfined porous media has been formulated mathematically by number of differential equations. Abdelsadek [12] proposed new trend for the solution of differential equation of drawdown near a pumping well using the finite-difference technique. Recently, the dispersion of concentration of waste-waters through confined or unconfined porous media was studied by number of researchers among home were Abdelsadek, Ali and Rashwan [12,13,14] , De Josselin [15] and Yih [16] .

Some experimental studies were carried out to show the effect of sulfate and chloride attack on the damage of R.C. elements. Effect of diffused salt concentration by sewage waters, from multiple seepage pits, through a confined porous media on the load carrying capacity of underground R.C. columns was analytically studied [17]. But, the influence of chloride and sulfate salts solutions diffused by sewage water through unconfined porous media on the expected deterioration and corrosion damage of underground R.C. elements, specially footings and necks of columns, after along period of time have not been enough studied. These researches need more time to give us an expected relation between the total relative concentration and time of exposure to these salts and their future damage effect on the properties of underground R.C. elements at any service time .

So, in this paper is developed the analytic program containing new equations for the determination of the effect of the induced chloride and sulfate salts by sewage water through unconfined porous media on the future corrosion damage and deterioration of concrete in underground R.C. elements specially necks of columns. The finite difference technique is used and a computer program is developed and written in a basic language for the solution of the problem in an unconfined porous media . The correction or reduction factors of concrete compressive strength " $\mathrm{CFc}$ ' and steel yield stress "CFs", longitudinal strain of concrete and corrosion rate of steel bars are determined as a function of total relative concentration of chloride and sulfate salts " $\mathrm{Ca} / \mathrm{Co}$ ", time level ,distance from the source of sewage disposal and soil properties and compared with the similar concrete elements not exposed to these sewage water. 


\section{THEORY}

\section{I) Single Recharge Sewage Resource}

The problem of unsteady radial flow of sulfate and chloride salt solutions from a recharging sewage source penetrating an unconfined porous media (as shown in Fig.1) can be formulated mathematically by the following system of equations [10, $12,13,14,16]$.

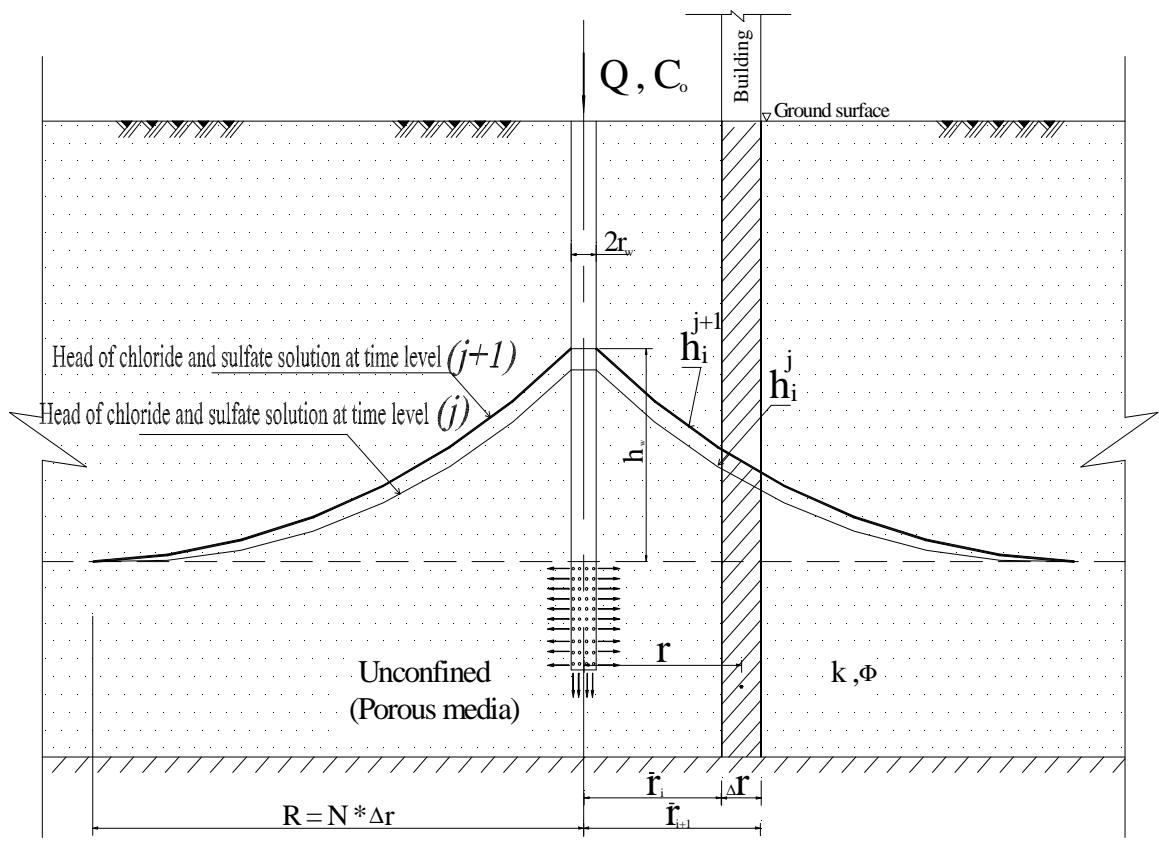

Fig. 1: Radial flow of sulfate and chloride salt solutions from a recharge sewage source penetrating an unconfined porous media.

\section{1) Equation of piezometric head of the salt solutions}

The piezometric head of induced sulfate and chloride salt solutions by sewage water through unconfined porous media at any point in the flow field of a recharging sewage source can be given by the following partial differential equation:

$$
\partial^{2} \mathrm{~h} / \partial \mathrm{r}^{2}+1 / \mathrm{r} * \partial \mathrm{h} / \partial \mathrm{r}=\mathrm{S} / \mathrm{T} * \partial \mathrm{h} / \partial \mathrm{t}
$$

Where : "h" = piezometric head ," $\mathrm{r}$ " = radial distance from the center line of a sewage source to the point at the chosen building at which required the piezometric head "h" , "S" = storage coefficient," T" = coefficient of transmissibility of the porous media and "t "= time at which required the piezometric head of the salt solutions .

2) Equation of dispersion of concentration of salt solutions: The dispersion of concentration " $\mathrm{C}$ " of sulfate and chloride salt solutions from sewage water through an unconfined porous media at any point at a radial distance " $r$ " from the sewage source may be expressed as $[12,13,14]$ : 


$$
1 / \mathrm{r} * \partial / \partial \mathrm{r}\left(\mathrm{r} . \mathrm{k}_{\mathrm{r}} \cdot \partial \mathrm{C} / \partial \mathrm{r}\right)-1 / \mathrm{r} * \partial / \partial \mathrm{r}(\mathrm{r} . \mathrm{U} \cdot \mathrm{C})=\partial \mathrm{C} / \partial \mathrm{t}
$$

In which: $\mathrm{U}=$ the pore velocity, which may be given in the form:

$$
\mathrm{U}=\mathrm{k} / \phi * \partial \mathrm{h} / \partial \mathrm{r}
$$

Where: $\quad \mathrm{k}=$ coefficient of permeability, $\phi=$ porosity of the soil and $\mathrm{k}_{\mathrm{r}}=$ radial dispersion coefficient which is a function of both pore velocity and the grain size of the soil "ds" and it can be given in the form : $\mathrm{k}_{\mathrm{r}}=0.86 \mathrm{ds}$. $\mathrm{U}$

At any point in the flow field of sewage source where the pore velocity and the dispersion coefficient are constants, Eqn. (2) may be expressed as:

$$
\mathrm{K}_{\mathrm{r}} * \partial^{2} \mathrm{C} / \partial \mathrm{r}^{2}-\mathrm{U} * \partial \mathrm{C} / \partial \mathrm{r}=\partial \mathrm{C} / \partial \mathrm{t}
$$

The initial and boundary conditions are:

$$
\begin{array}{lll}
\mathrm{h}(\mathrm{r}, 0)=0, \mathrm{~h}(\infty, \mathrm{t})=0 & \mathrm{t} \geq 0 & \text { for piezometric head equation } \\
\operatorname{lime} 2 \prod \cdot \mathrm{r} \cdot \mathrm{T} \partial \mathrm{h} / \partial \mathrm{r}=\mathrm{Q} & \mathrm{t} \geq 0 & \\
\mathrm{C}(\mathrm{r}, 0)=0, \mathrm{C}\left(\mathrm{r}_{\mathrm{w}}, \mathrm{t}\right)=\mathrm{Co}, \mathrm{C}(\infty, \mathrm{t})=0 & \mathrm{t} \geq 0 \\
\mathrm{r}_{\mathrm{w}}=\text { radius of the sewage source or well } &
\end{array}
$$

The solution of the piezometric head or surface equation (Eqn .1) of the salt solution was obtained by Theis [10] for homogenous porous media in the form:

$$
\mathrm{h}(\mathrm{r}, \mathrm{t})=(\mathrm{Q} / 4 \Pi . \mathrm{T}) * \mathrm{~W}(\mathrm{u})
$$

Where: $\mathrm{Q}=$ recharge value of the sewage source ,

$$
\begin{aligned}
& W(u)=-\operatorname{Ei}(u)=\int_{u}^{\infty}\left(e^{-u} / u\right) \cdot d u \\
& U=r^{2} * h /(4 \text { T. } t)
\end{aligned}
$$

Abdelsadek et al.[12, 14, 15] proposed the theory for the determination of the drawdown and concentration of migrating salts near a recharge well under unsteady state conditions using the finite- difference technique. The theory was briefly explained in the previous works and applied for both confined and unconfined porous media. For the solution of the system of equations written at the nodes $1,2,3, \mathrm{~N}$, $\mathrm{N}-1$, the values of $\mathrm{a}(\mathrm{I}, \mathrm{J}), \mathrm{b}(\mathrm{I}, \mathrm{J}), \mathrm{f}(\mathrm{I}, \mathrm{J})$ should be firstly determined from the previous given values of $\mathrm{k}_{\mathrm{r}}(\mathrm{I}, \mathrm{J}), \mathrm{U}(\mathrm{I}, \mathrm{J})$. Then: $\mathrm{A}(2, \mathrm{~J}), \mathrm{B}(2, \mathrm{~J}+1)$ are calculated by using equations , then $\mathrm{A}(3, \mathrm{~J}), \mathrm{B}(3, \mathrm{~J}+1), \mathrm{A}(4, \mathrm{~J}), \mathrm{B}(4, \mathrm{~J}+1)$, . $\mathrm{A}(\mathrm{N}+1, \mathrm{~J}), \mathrm{B}(\mathrm{N}+!, \mathrm{J}+1)$ can be determined .

Using the lower boundary condition $[\mathrm{C}(\mathrm{N}+1, \mathrm{~J}+1)=0]$ and the obtained coefficients, the known values of $\mathrm{C}(\mathrm{N}, \mathrm{J}+1), \mathrm{C}(\mathrm{N}-1, \mathrm{~J}+1), \ldots . \mathrm{C}(1, \mathrm{~J}+1)$ at all nodes in the backward direction at the level "J+1" can be determined . Similarly, the calculations are continued to find $\mathrm{C}(\mathrm{I}, \mathrm{J}+2), \mathrm{C}(\mathrm{I}, \mathrm{J}+3), \ldots . . \mathrm{C}(\mathrm{I}, \mathrm{J}+\mathrm{M})$ at time levels "J+2" , "J+3" , ....and "J+M" respectively . A computer program was developed and written to formulate the model.

\section{II) Multiple Recharge Sewage Sources Penetrating An Unconfined Porous Media}

When a group of sewage sources situating near each other's are recharging, their drawdown curves intersect within their radius of influence. The total piezometric 
head of salt solutions at any underground building at a point "A" in their flow field ( as shown in Fig. 2) is equaling to the sum of the piezometric heads caused by each sewage source individually . Thus:

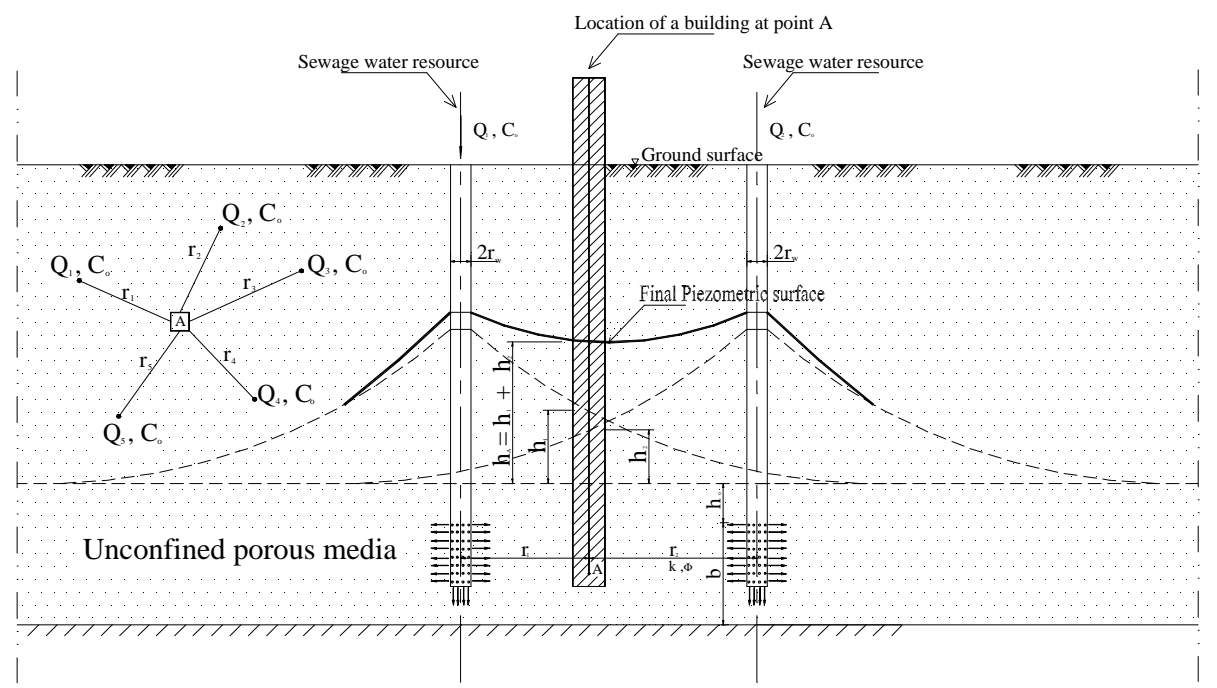

Fig.(2) : Total piezometric head of diffused sodium sulfate \& chloride salt solutions flow from multiple sewage sources.

$$
\mathrm{h}_{\mathrm{A}}=\mathrm{h}_{1}+\mathrm{h}_{2}+\mathrm{h}_{3}+\ldots \ldots . . . \mathrm{h}_{\mathrm{n}}
$$

In which " $n "$ = number of interfered sewage sources.

Similarly, the concentration of diffused salt solutions at point "A" in the flow field of "n" sewage sources is:

$$
\mathrm{C}_{\mathrm{A}}=\mathrm{C}_{1}+\mathrm{C}_{2}+\mathrm{C}_{3}+
$$

From the foregoing, it is appeared that, the concentration of diffused salts at any point in the flow field of interfered recharge sewage sources " $\mathrm{C}_{\mathrm{A}}$ " is a function of the initial concentration " $\mathrm{C}_{\mathrm{o}}$ ", the soil permeability coefficient " $\mathrm{k}$ ", the soil porosity " $\phi "$ , the diameter of the soil particles " $\mathrm{d}_{\mathrm{s}}$ " , the radial distance from the source and the time " $\mathrm{t}$ ". Therefore:

$$
\mathrm{C}_{\mathrm{A}}=\mathrm{f}\left(\mathrm{C}_{\mathrm{o}}, \mathrm{k}, \phi, \mathrm{d}_{\mathrm{s}}, \mathrm{r}, \mathrm{t}\right)
$$

\section{3) Developed equations of the expected damage of R.C. columns in a building at point " $A$ " in the flow field of sewage water through unconfined porous media .}

After calculating the total concentration of sulfate and chloride salt solutions $\mathrm{C}_{\mathrm{T}}(\mathrm{I}, \mathrm{J})$ at any block "I" and time level "J" or $\mathrm{C}_{\mathrm{T}}(\mathrm{I}, \mathrm{J}+1)$ at time level "J+1" , the total relative concentration " $\mathrm{C}_{\mathrm{R}}$ "at a building at point " $\mathrm{A}$ " can be determined from the following equation : 


$$
\mathrm{C}_{\mathrm{R}}(\mathrm{I}, \mathrm{J}+1)=\mathrm{C}_{\mathrm{T}}(\mathrm{I}, \mathrm{J}+1) / \mathrm{C}_{\mathrm{o}}
$$

Where: $\mathrm{C}_{0}=$ initial concentration of sulfate $\&$ chloride salts at each sewage source , $\mathrm{C}_{\mathrm{T}}(\mathrm{I}, \mathrm{J}+1)=$ total concentration of diffused salts at block "I" and time level "J+1" The expected values of corrosion rate of embedded steel bars " $\mathrm{C}_{\mathrm{r}}$ ", reduction factors of concrete compressive strength " $\mathrm{CF}_{\mathrm{c}}$ " and steel yield stress " $\mathrm{CF}_{\mathrm{s}}$ " and longitudinal strain of concrete " $€_{\mathrm{c}}$ " for underground R.C. columns in the chosen building at any service time " $\mathrm{t}$ " can be determined from the following developed equations depending on the total relative concentration of salt solutions and time of exposure to these salts.

$$
\begin{aligned}
& \mathrm{Cr}(\mathrm{I}, \mathrm{J}+1)=\left[0.1 \sqrt{ } \mathrm{t} * 0.27 \mathrm{C}_{\mathrm{R}}(\mathrm{I}, \mathrm{J}+1)\right]+0.579 \\
& \mathrm{CFc}(\mathrm{I}, \mathrm{J}+1)=[1.0-0.12 * \sqrt{ } \mathrm{Cr}(\mathrm{I}, \mathrm{J}+1)] \\
& \mathrm{CFs}(\mathrm{I}, \mathrm{J}+1)=[1.0-0.062 * \sqrt{\mathrm{Cr}}(\mathrm{I}, \mathrm{J}+1)] \\
& € \mathrm{c}(\mathrm{I}, \mathrm{J}+1)=\left[3.266 \times 10^{-4}+6.92 \times 10^{-7} * \mathrm{Cr}(\mathrm{I}, \mathrm{J}+1) \sqrt{\mathrm{t}}\right]
\end{aligned}
$$

The actual expected compressive strength of concrete $\mathrm{Fc}(\mathrm{I}, \mathrm{J}+1)$ and yield stress of steel bars Fy (I , J+1) of underground R.C. columns situated in the chosen building at a point "A" at block "I" and distance "ri" from multiple sewage sources can be determined at any time level "J+1" from the following equations :

$$
\begin{aligned}
& \mathrm{Fc}(\mathrm{I}, \mathrm{J}+1)=[\mathrm{CFc}(\mathrm{I}, \mathrm{J}+1) * \mathrm{Fcu}] \\
& \mathrm{Fs}(\mathrm{I}, \mathrm{J}+1)=[\mathrm{CFs}(\mathrm{I}, \mathrm{J}+1) * \mathrm{Fy}]
\end{aligned}
$$

Where: $\mathrm{Fcu}=$ cubic compressive strength of concrete after 28 days,

$\mathrm{Fy}=$ yield stress of steel reinforcement of R.C. column

\section{COMPUTER IMPLEMENTATION}

i) Computer program: A computer program was written for use with IBM personal computer. Figure 3 shows the flow chart of essential features of the program containing the developed new equations for the future mechanical properties losses of necks of R.C. columns damaged by sewage water flow.

ii) Range of variable parameters: The number of multiple sewage water sources, surrounding a chosen building at point referred to "A" changes from 1 to 5 (as shown in Fig. 2). The sewage sources, that having recharge values of $\mathrm{Q}_{1}=2 \mathrm{Q}_{2}=$ $4 Q_{3}=10 Q_{4}=20 Q_{5}=200 \mathrm{~m} 3 /$ day are at a variable distances $\left(r_{1}=250 \mathrm{~ms}, r_{2}=204 \mathrm{~ms}\right.$, $\mathrm{r}_{3}=160 \mathrm{~ms}, \mathrm{r}_{4}=113 \mathrm{~ms}, \mathrm{r}_{5}=45 \mathrm{~ms}$ ) from the chosen building at point "A". The diameter of the soil particles "ds" equals to $0.6 \mathrm{~mm}$ with different values of soil porosity " $\phi$ " $=0.35,0.40,0.45$. The permeability coefficient of soil " $k$ " is changed from $10 \mathrm{~m} /$ day to $150 \mathrm{~m} /$ day. The storage coefficient "S" is assumed to be constant at 0.007 . The transmissibility coefficient $[\mathrm{T}(\mathrm{I}, \mathrm{J})]$ for unconfined porous media is taken as a function of head value[h(I,J)] of chloride and sulfate salts solutions and permeability coefficient at any point at a radial distance " $r_{i}$ " from the sewage source. The initial concentration "Co' of the sulfate and chloride salt solutions at each sewage source is assumed to be constant and equals 3000p.p.m. The initial concrete compressive strength was assumed to be $250 \mathrm{~kg} / \mathrm{cm}^{2}$ and steel yield stress to be $2800 \mathrm{~kg} / \mathrm{cm}^{2}$. 


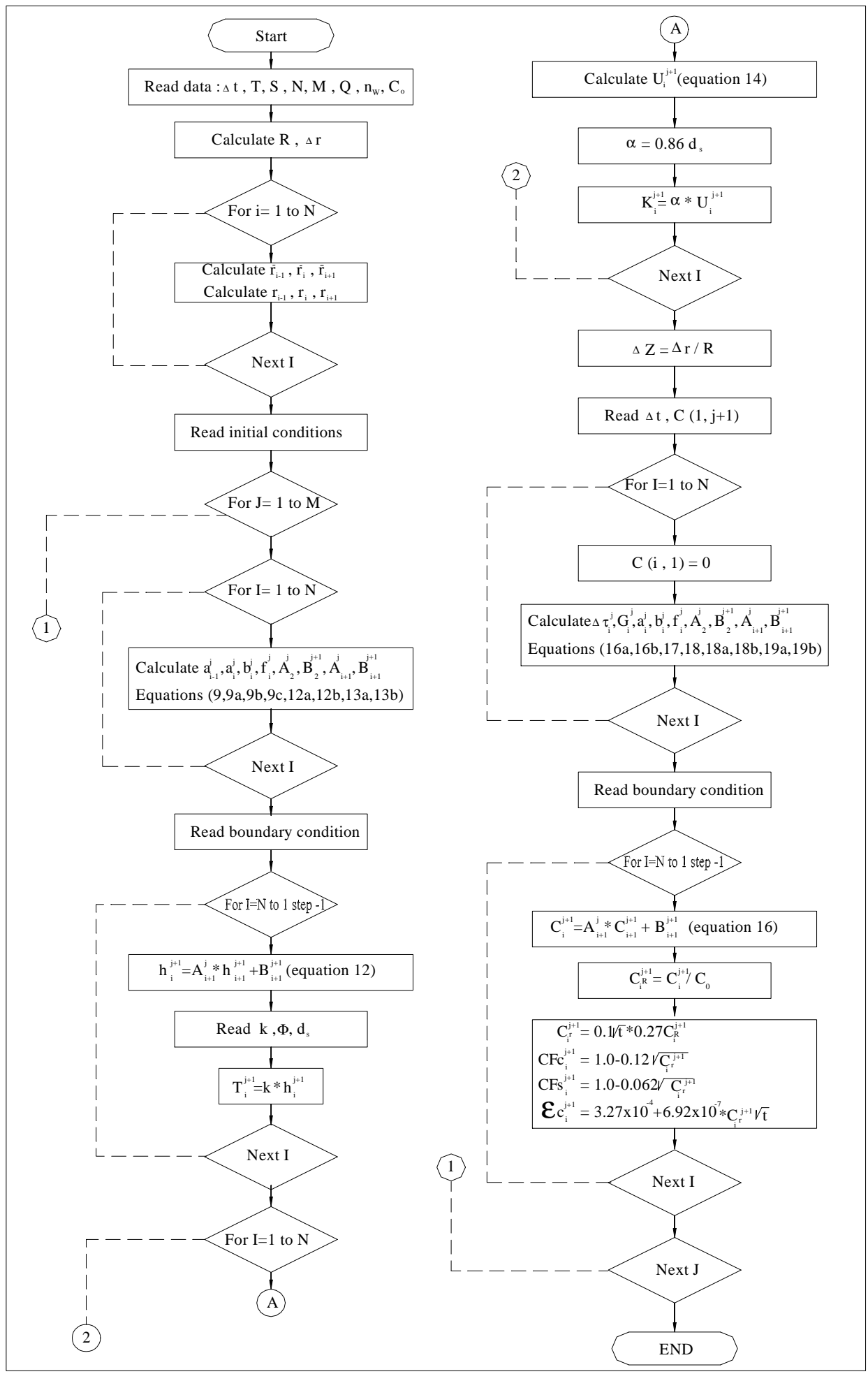

Fig. 3: Flow chart for computer program. 


\section{RESULTS AND DISCUSSIONS}

In the model, the time increment $(\Delta \mathrm{t})$ and the number of divisions $(\mathrm{N})$ have great influence on the consistency of computation of the total head of salt solutions flow and hence on their concentration values. After number of trials, the numeric calculations are performed using $\Delta \mathrm{t}=0.5$ days and " $\mathrm{N} "=50$ blocks which having an accuracy for the computed total head values after the decimal point.

\section{1) Effect of time and soil properties ( $k \& \phi)$ on the total head of salt solutions, induced by multiple sewage water resources through unconfined porous media, at the suggested building}

Effect of soil properties $(\mathrm{k} \& \phi)$ and time of exposure of any underground R.C. building to sodium sulfate and chloride salt solutions, induced by five multiple sewage water resources penetrating an unconfined porous media, on their total piezometric head is analytically studied. The numerical results are determined for different values of soil properties $(\mathrm{K}=10,25,50,100 \& 150 \mathrm{~m} / \mathrm{day}, \phi=0.35,0.4, \&$ $0.45)$, diameter of soil particles " $\mathrm{ds} "=0.6 \mathrm{~mm}$, and for different times. The results are plotted in figure $\mathbf{4}$ assuming the previous suggested data of the chosen building and sewage sources.

Figure 4a shows that, the total head of diffused chloride and sulfate salt solutions $d$ by sewage waters at the chosen underground building is clearly affected by the soil permeability at the same porosity of soil. It is largely increased by increasing soil permeability to $25 \mathrm{~m}$ /day and slowly decreased by increasing soil permeability to $150 \mathrm{~m} /$ day at any time. It is necessary to notice that, the soil porosity " $\Phi$ " and time of exposure to these salts " $t$ " have a neglected influence on the value of total head of salt solutions at the chosen building (as shown in Fig. 5b). This may be explained that, by increasing permeability coefficient, the pore velocity increases which leads to the decrease of salt solutions head.

(a)

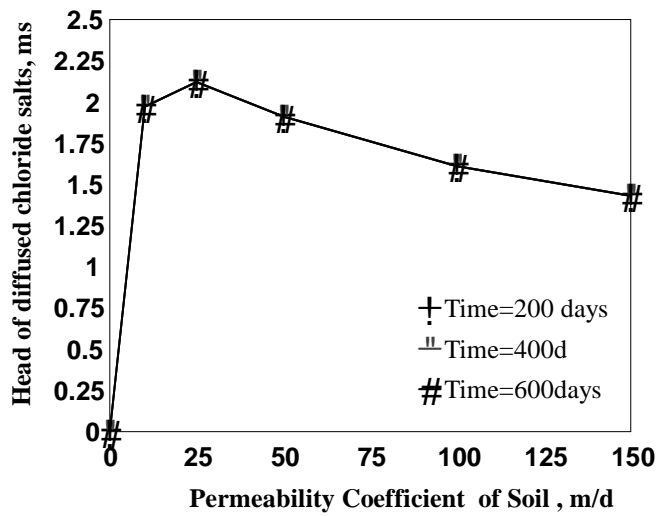

(b)

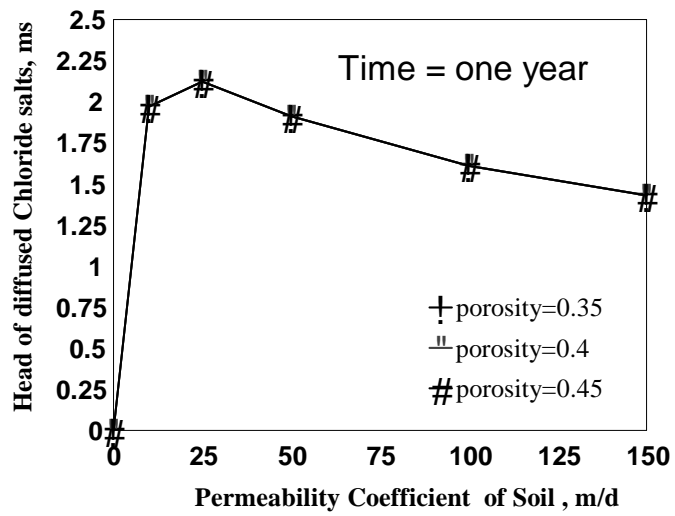

Fig. 4: Effect of soil properties and time on the total piezometric head " $\mathbf{h}_{\mathbf{a}}$ " of sulfate and chloride solutions at the chosen building at point " $A$ ".

(a) " $h_{a}$ " versus soil permeability at different times $(\Phi=0.4)$,

(b) " $h_{a}$ " versus soil permeability at different values of soil porosity 


\section{2) Influence of time and soil properties on the total relative concentration " $\mathrm{C}_{A} / \mathrm{C}_{O}$ " of sulfate and chloride solutions, induced by sewage water resources through unconfined porous media, at the chosen R.C. building}

The same suggested data are used to determine the total relative concentration " $\mathrm{C}_{\mathrm{A}} / \mathrm{Co}$ " of the diffused salt solutions from five multiple sewage resources through unconfined porous media to the chosen building at point "A" in their flow field taking the effect of soil properties and time of exposure to these salts into consideration. The numerical results are determined and plotted in figure 5.

(a)

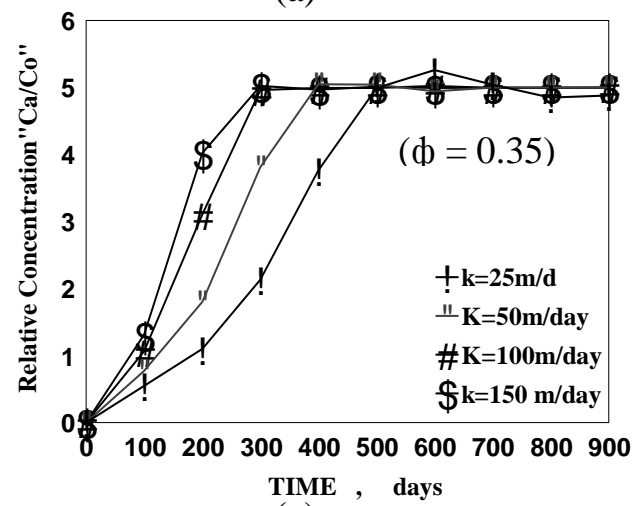

(c)

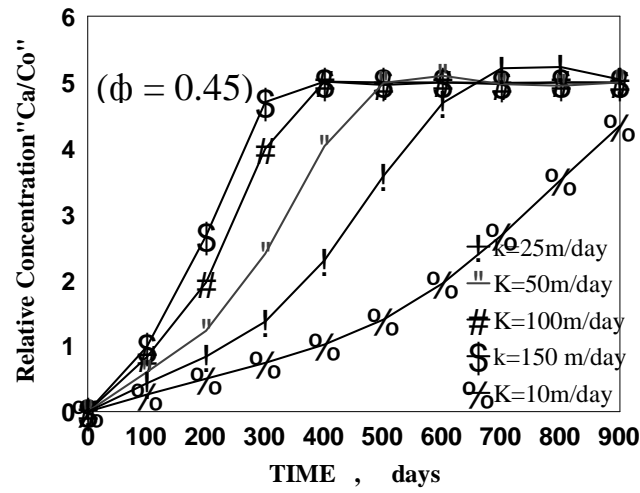

(b)

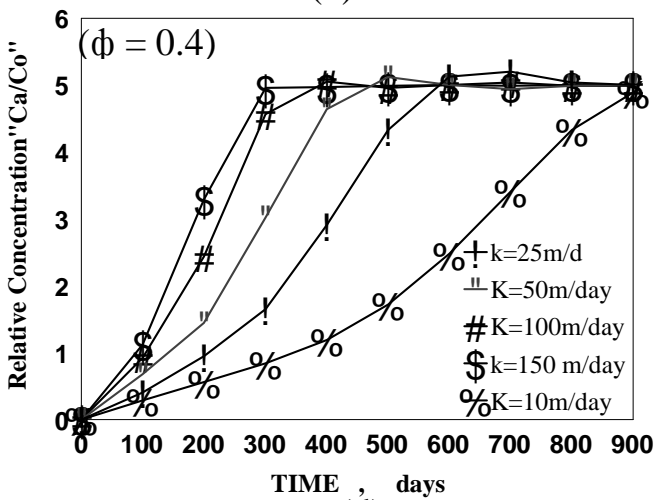

(d)

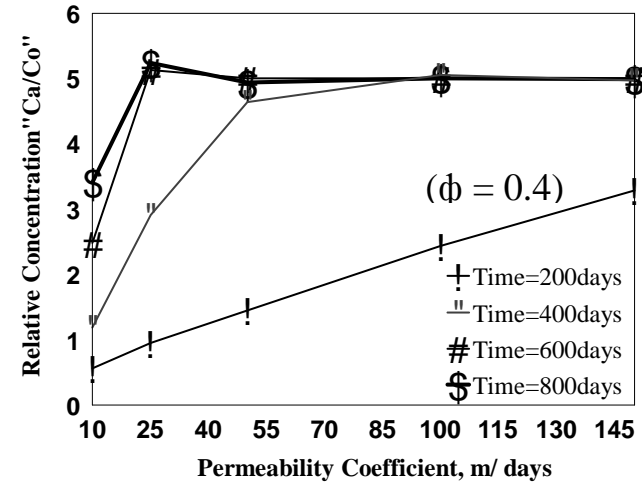

Fig. 5: Effect of soil properties and time on the total relative concentration " $\mathrm{C}_{A} / \mathrm{C}_{0}$ " of sulfate and chloride solutions at the chosen underground building.

a) $" \mathrm{C}_{\mathrm{A}} / \mathrm{C}_{0}$ " versus time at different permeability coefficients $(\phi=0.35)$,

b) " $\mathrm{C}_{\mathrm{A}} / \mathrm{C}_{0}$ " versus time at different permeability coefficients $(\phi=0.4)$,

c) $" \mathrm{C}_{A} / \mathrm{C}_{0}$ " versus time at different permeability coefficients $(\phi=0.45)$, and

d) $" \mathrm{C}_{\mathrm{A}} / \mathrm{C}_{0}$ " versus soil permeability at different times, ( $\left.\phi=0.4\right)$

Figures $5 \mathbf{a}, \mathbf{b}, \mathbf{c}$ show the total relative concentration of the induced sulfate and chloride solutions, from five sewage water resources at a building at point "A", versus time at different permeability coefficients and porosity of soil $(\phi=0.35,0.4$, 0.45 ) respectively. As expected, the total relative concentration of the diffused salts 
at the chosen underground building increases gradually and rapidly with the time approaching the unity or bigger than that value after a time depending mainly on the permeability coefficient, porosity of soil, radial distance from the sewage resource and number of sewage resources.

Again, the numerical results of $" \mathrm{C}_{\mathrm{A}} / \mathrm{C}_{\mathrm{o}} "$ are plotted in Fig. 5d against soil permeability for different times and constant soil porosity $(\phi=0.4)$. Obviously, the total relative concentration of the proposed salts at the chosen building rapidly increases ( from 1.19 to 4.97 ) by increasing soil permeability from $10 \mathrm{~m} / \mathrm{day}$ to $150 \mathrm{~m} /$ day at time level equals one year. But, after 2 years, $" \mathrm{C}_{\mathrm{A}} / \mathrm{C}_{\mathrm{o}}$ " increases from 3.41 to 5 for the same values of soil permeability. It is necessary to notice that, the soil porosity has a small effect on the values of $" \mathrm{C}_{\mathrm{A}} / \mathrm{C}_{\mathrm{o}}$ " compared to the soil permeability. The relative concentration increases by decreasing the value of soil porosity. At time $=200$ days, and $\mathrm{k}=100 \mathrm{~m} /$ day, $" \mathrm{C}_{\mathrm{A}} / \mathrm{C}_{\mathrm{o}}$ " increases from 1.96 to 3.11 by decreasing porosity of soil from 0.45 to 0.35 (as shown in Table 1). Obviously, the total relative concentration at the chosen building reaches the number of sewage water resources after about 400 days for the suggested properties of the unconfined porous media. This may be explained by the good effect of soil permeability and porosity on increasing pore velocity and diffusion of sodium sulfate and chloride salts from the suggested sewage water resources penetrating unconfined porous media.

Table 1: effect of soil porosity " $\phi$ " on the relative concentration of the diffused salts from five sewage water resources through unconfined porous media ( $k=100 \mathrm{~m} / \mathrm{day})$.

\begin{tabular}{|l|l|l|l|l|l|l|l|l|}
\hline $\begin{array}{l}\text { Soil } \\
\text { porosity }\end{array}$ & \multicolumn{7}{|c|}{ Relative concentration “ $\mathrm{C}_{\mathrm{A}} / \mathrm{C}_{\mathrm{o}}$ " } & at time, days \\
\cline { 2 - 10 } & 100 & 200 & 300 & 400 & 500 & 600 & 700 & 800 \\
\hline$\Phi=0.35$ & 1.063 & 3.110 & 4.960 & 4.99 & 4.99 & 5.02 & 4.99 & 5.00 \\
\hline$\Phi=0.40$ & 0.986 & 2.434 & 4.563 & 5.05 & 4.96 & 5.00 & 5.01 & 4.99 \\
\hline$\Phi=0.45$ & 0.830 & 1.960 & 3.990 & 5.01 & 5.00 & 5.00 & 5.00 & 5.00 \\
\hline
\end{tabular}

\section{3) Prediction of the corrosion of steel bars and deterioration of concrete in the chosen R.C. building damaged by sodium sulfate and chloride solutions}

The chemical resistance of underground R.C. elements exposed to sulfate and chloride salt solutions, induced by sewage water resources through unconfined porous media, is expressed by the percentage of their mechanical properties losses. These disadvantages are the increase of corrosion rate of embedded steel bars, increase of strain and deformation of concrete, decrease of concrete compressive strength \&steel yield stress and cracking of the concrete cover.

\section{3.a) Corrosion damage of embedded steel bars}

\section{3.a.1) Future corrosion rate of embedded steel bars $\mathrm{Cr}(\mathrm{I}, \mathrm{J})$}

The same previous data are used and numerical calculations are extended to find the effect of the unconfined porous media properties and time of exposure of the chosen underground R.C. building to the suggested salt solutions on the future corrosion rate 
of embedded steel bars of its columns. The results are determined at any time level, depending on the development of some experimental results [3,18], from the suggested equation (No.10) and plotted in figure 6.

(a)

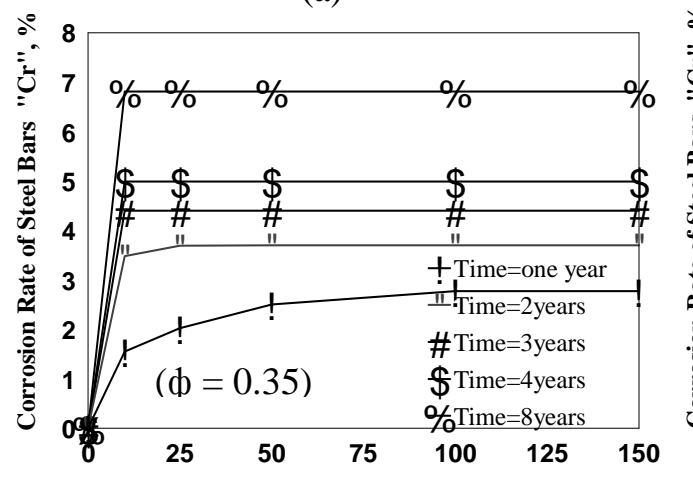

Permeability Coefficient of Soil, $\mathbf{m} / \mathbf{d}$

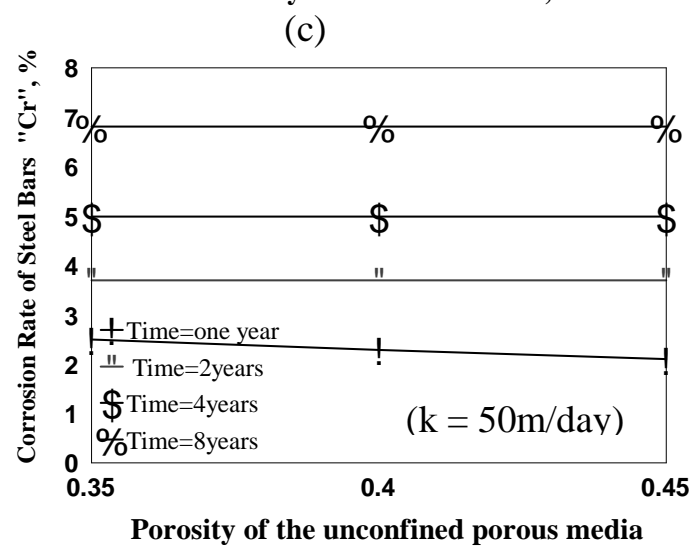

(b)

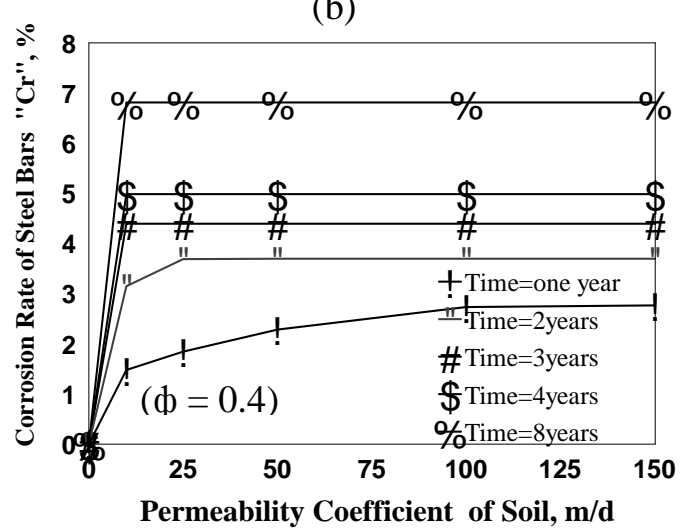

(d)

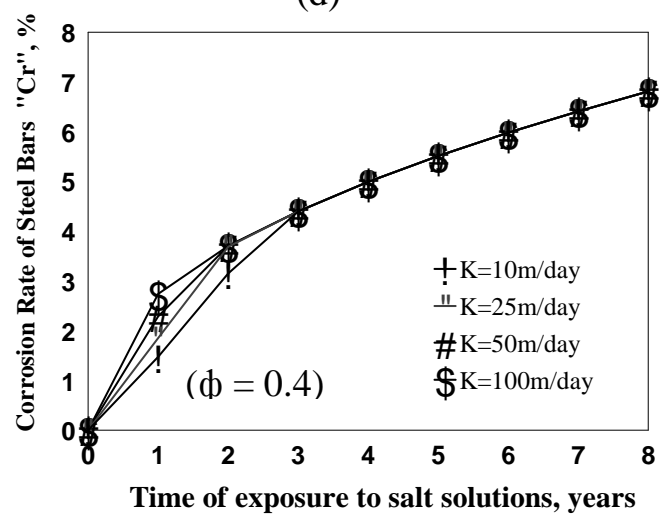

Fig. 6: Effect of soil properties and time on the corrosion rate " $\mathrm{Cr}$ "of embedded steel bars in R.C. columns damaged by sulfate and chloride salt solutions
a) " $\mathrm{Cr}$ " versus permeability coefficients at different times ( $\phi=0.35)$,
b) " $\mathrm{Cr}$ " versus permeability coefficients at different times $(\phi=0.40)$,
c) " $\mathrm{Cr}$ " versus porosity of soil at different times ( $\mathrm{k}=50 \mathrm{~m} /$ day), and
d) " $\mathrm{Cr}$ "versus time at different soil permeability $(\phi=0.4)$

Figures $6 \mathbf{a}, \mathbf{b}$ show the corrosion rate of embedded steel bars of columns, in underground R.C. building damaged by the flow of sulfate and chloride salt solutions from multiple sewage resources, versus soil permeability at different times and for soil porosity equals $0.35 \& 0.40$ respectively. As expected, corrosion rate of embedded steel bars of R.C. columns in the chosen underground building is clearly affected by the total relative concentration of salt solutions " $\mathrm{C}_{\mathrm{A}} / \mathrm{C}_{\mathrm{o}}$ ", time of exposure to these salts " $\mathrm{t}$ ", and properties of the unconfined porous media until 2years. After 2 years, the effect of soil permeability is neglected. It is necessary to notice that, the time of exposure to these salts have a large effect on increasing future corrosion 
damage of steel bars especially after 2 years. At soil properties $(K=100 \mathrm{~m} / \mathrm{d}, \phi=0.4$ and $\mathrm{ds}=0.6 \mathrm{~mm}$ ), future corrosion rate of embedded steel bars in R.C. columns will be equal to $2.74 \%$, by weight, after one year. But, It will be equal to $6.8 \%$, by weight, after 8 years for the proposed data in the problem in this research.

Figure 6c shows the effect of soil porosity " $\phi=0.35,0.4 \& 0.45$ " on the future corrosion rate of steel bars in the chosen underground building and for soil permeability $=50 \mathrm{~m} /$ day. Obviously, the soil porosity has a small effect on the corrosion rate of embedded steel bars compared to the effect of permeability coefficient at the same time and the same previous data of salts and building situation. After one year, corrosion rate, by the reduction of weight, slowly decreases from 2.77 to $2.54 \%$ by increasing soil porosity from 0.35 to 0.45 with constant $\mathrm{k}=$ $50 \mathrm{~m} / \mathrm{day}$. It is necessary to notice that, the effect of the properties of the unconfined porous media $(\mathrm{k}, \phi)$ on the future corrosion rate of steel bars is neglected after 2 years of exposure of the chosen building to the suggested salt solutions flow from sewage waters. But, the actual parameter affecting the corrosion rate of steel is the long time of exposure to these salts (as shown in figure 6.d). From which is clear the effectiveness of long time on increasing corrosion rate of steel bars " $\mathrm{Cr}^{\text {" }}$ and at the same time, the effect of soil properties disappeared. This may be explained as previously stated, the ferrous chloride phenomenon in the presence of oxygen is in adequate to explain the generated corrosion damage of embedded steel bars. This consequently leads to the increase of corrosion rate of embedded reinforcement.

\section{3.a.2) Reduction factor of future steel yield stress $\mathrm{CFs}(\mathrm{I}, \mathrm{J})$ at the chosen building at distance " $r_{i}$ " and time level " $J$ "}

The numerical results are determined, for the same data of the chosen underground building, to find the effect of the porous media properties $(\mathrm{k}, \phi)$ and time of its exposure to the suggested salt solutions flow on the future yield stress " $\mathrm{Fy}_{\mathrm{f}}$ ' of embedded steel bars in its R.C. columns. The results are calculated at the chosen building and plotted in Fig. 7 at any time level from the following equation:

$\mathrm{Fy}_{\mathrm{f}}(\mathrm{I}, \mathrm{J})=\mathrm{CFs}(\mathrm{I}, \mathrm{J}) * \mathrm{Fy}$, where: $\mathrm{CFs}(\mathrm{I}, \mathrm{J})$ is the reduction factor of steel yield stress of columns at a distance (I) from the sewage source and time level (J). It is determined from the following equation developed from the expected corrosion rate: $\mathrm{CFs}(\mathrm{I}, \mathrm{J})=1.0-0.062 \sqrt{\mathrm{Cr}(\mathrm{I}, \mathrm{J})}$

Figures 7a, b show the reduction factor of future yield stress of steel "CFs " embedded in R.C. columns in the chosen building, damaged by the flow of suggested salt solutions, versus soil permeability at different times and for soil porosity $\phi=$ $0.35 \& 0.40$ respectively. Obviously, " CFs " is small affected by the porous media properties $(\mathrm{k}, \phi)$ until two years and the clearly effect occurs with soil permeability. As the soil permeability increases from $10 \mathrm{~m} /$ day to $150 \mathrm{~m} /$ day, " CFs " decreases from 0.92 to 0.90 after one year and for soil porosity $=0.4$. After 2 years, "CFs " decreases by about $12 \%$ for different values of soil properties compared to the same type of concrete not exposed to these salts. It is necessary to notice that, the soil porosity has a neglected effect on this factor at any time and for different values of soil permeability (as shown in Fig. 7c). 
(a)

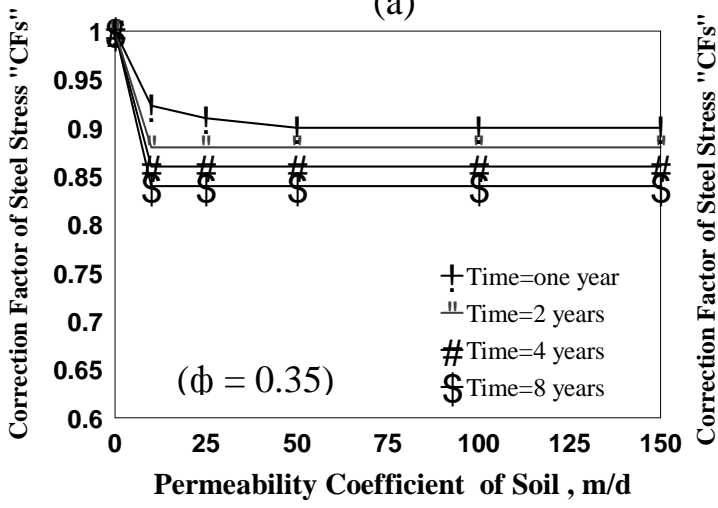

(c)

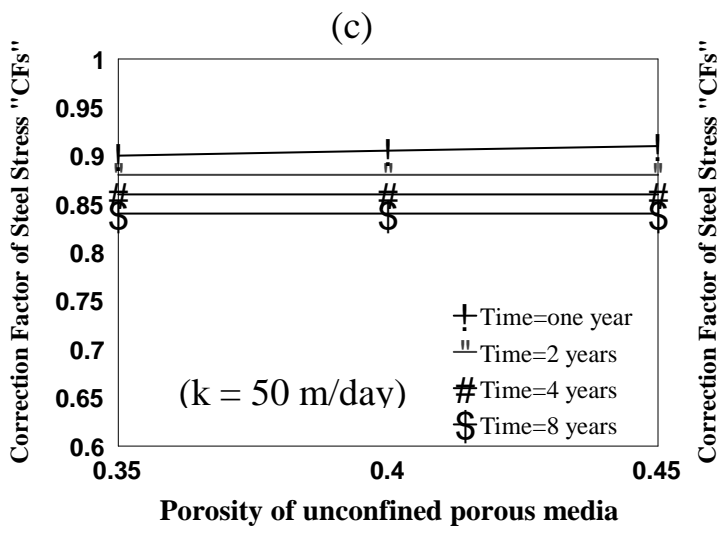

(b)

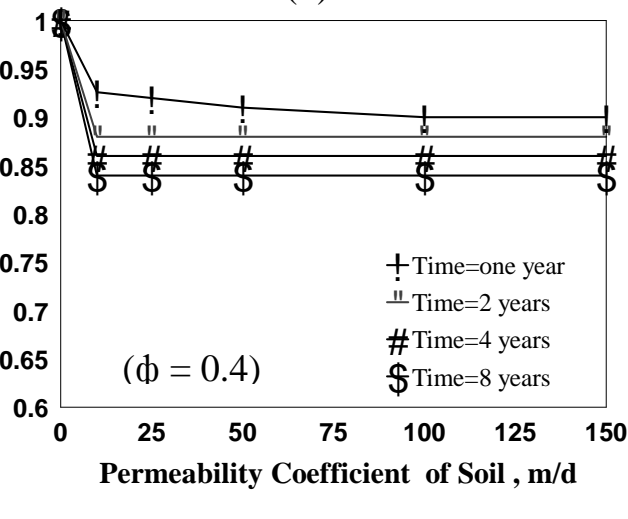

(d)

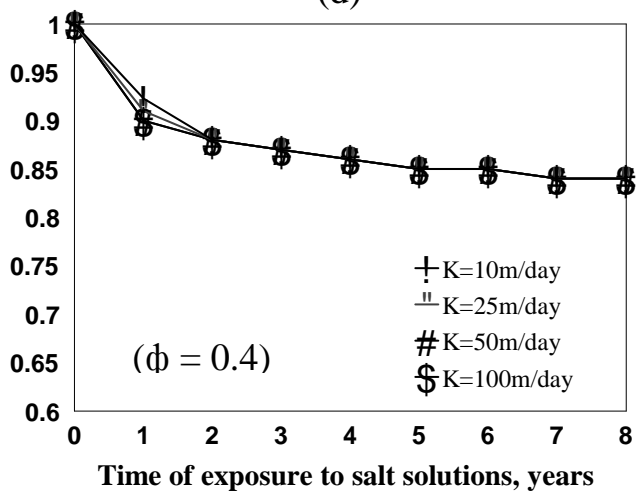

Fig. 7: Effect of unconfined porous media properties and time of exposure of the chosen underground building to sodium sulfate \&chloride salt solutions flow on the correction factor of future steel yield stress of its R.C. columns
a) "CFs " versus permeability coefficients at different times $(\phi=0.35)$,
b) "CFs "versus permeability coefficients at different times $(\phi=0.45)$,
c) "CFs" versus porosity of soil at different times ( $k=50 \mathrm{~m} /$ day), and
d) "CFs " versus time at different soil permeability coefficients $(\phi=0.4)$

Figure $\mathbf{7 d}$ shows the influence of a long time of exposure of the chosen building to the suggested salts on the reduction factor of yield stress of its damage column reinforcement. It is clear that the long time of exposure to these salt solutions has a clear and main influence on decreasing "CFs " compared to the effect of soil properties, which are neglected after 2 years. "CFs " decreases by about $16 \%$ (from 1.0 to 0.84 ) after 8 years compared to the same type of concrete (C250) not exposed to these salts induced by sewage waters. This may be explained by the effect of the long time of exposure to these salts on increasing corrosion rate and pitting corrosion of embedded reinforcement, which decreases its future yield stress. 


\section{3.b) Deterioration of concrete of the R.C. columns (C250) in the chosen underground building damaged by sodium sulfate \& chloride solutions}

\section{3.b.1) Reduction factor of concrete future compressive strength " CFc "}

The numerical calculations were extended, for the same previous data of the chosen underground building, to find the effect of the porous media properties $(\mathrm{k}, \phi)$ and time of its exposure to the suggested salt solutions flow on the future compressive strength ' $\mathrm{Fc}_{\mathrm{f}}$ ' of concrete of its R.C. columns. The numerical results were determined at the chosen R.C. building and plotted in Fig. 8 at any time level from the following developed equation:

$\mathrm{Fc}_{\mathrm{f}}(\mathrm{I}, \mathrm{J})=\mathrm{CFc}(\mathrm{I}, \mathrm{J}) * \mathrm{Fc}_{28}$, where: $\mathrm{CFc}(\mathrm{I}, \mathrm{J})=$ reduction factor of concrete compressive strength at any distance from the sewage resource and at any time. It is determined from the following equation developed from the expected corrosion rate: $\mathrm{CFc}(\mathrm{I}, \mathrm{J})=1.0-0.12 \sqrt{\mathrm{Cr}(\mathrm{I}, \mathrm{J})}$

Figures $\mathbf{8 a}$, $\mathbf{b}$ show the reduction factor of future compressive strength of concrete" $\mathrm{CFc}$ " of R.C. columns in the chosen building, damaged by the flow of suggested salt solutions, versus soil permeability at different times and for soil porosity $\phi=0.35 \&$ 0.40 respectively. Obviously, " $\mathrm{CFc}$ " is clearly affected by the corrosion rate of steel bars, which affected by the relative concentration of diffused salts and the porous media properties $(\mathrm{k}, \phi)$ until two years. As the soil permeability increases from $10 \mathrm{~m} /$ day to $150 \mathrm{~m} /$ day, " $\mathrm{CFc}$ " decreases from 0.85 to 0.79 after one year and for soil porosity $=0.35$. But, for soil porosity $=0.40$, it decreases from 0.85 to 0.80 after one year. So, the effect of soil permeability is greater than the soil porosity.. It is necessary to notice that, the effect of soil properties is neglected after 2 years (as shown in Fig. 8c). From this figure it is clearly that the negligible effect of the soil porosity on the factor " $\mathrm{CFc}$ " at the same permeability coefficient.

Figure 8d shows the relation between " $\mathrm{CFc}$ " along period of time of exposure to these salts at different permeability coefficients and for soil porosity $\phi=0.40$. Obviously, the effectiveness of the long time of exposure to these salt solutions on decreasing " $\mathrm{CFc}$ " compared to the effect of porous media properties, which were neglected after 2 years. After 8 years, " $\mathrm{CFc}$ " decreased by about $31.4 \%$ (from 1 to 0.686) for different values of soil properties compared to the same type of concrete (C250) not exposed to these salts. This may be explained by the effect of the long time of exposure to these salts on increasing corrosion rate and pitting corrosion of embedded reinforcement, internal cracks of concrete and deterioration of concrete cover due to sulfuric acids and chloride ions, which consequently decrease its future compressive strength.

\section{3.b.2) Future longitudinal concrete strain " $\epsilon c_{f}$ " of the R.C. columns (C250)}

The investigations were continued, for the same previous data of the chosen underground building, to find the effect of the porous media properties $(\mathrm{k}, \phi)$ and time of its exposure to the suggested salt solutions flow on the future longitudinal strain " $\mathrm{Cc}_{\mathrm{f}}$ " of concrete of its R.C. columns. The numerical results were determined at the chosen R.C. building and plotted in Fig. 9 at any time level from the following 
equation developed from the expected corrosion rate of steel bars and some previous experimental data $[3,18]$ :

$\mathrm{Ec}_{\mathrm{f}}(\mathrm{I}, \mathrm{J})=3.27 \times 10^{-4}+6.92 \times 10^{-7} * \mathrm{Cr}(\mathrm{I}, \mathrm{J}) * \sqrt{\mathrm{t}}$, where: $\mathrm{t}=$ time in days.

(a)

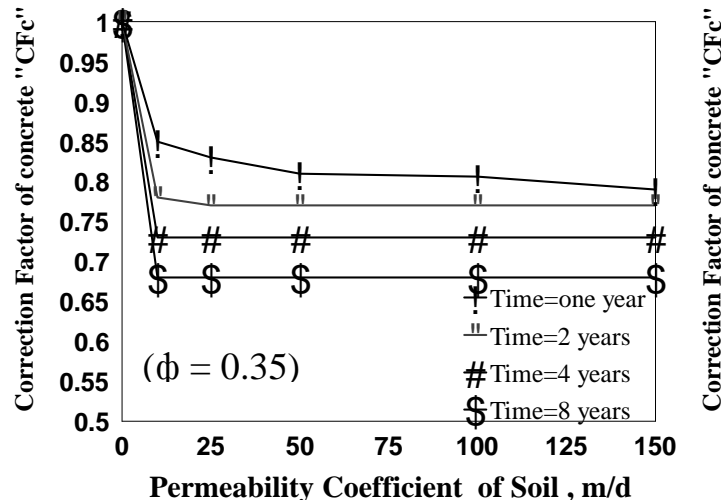

(c)

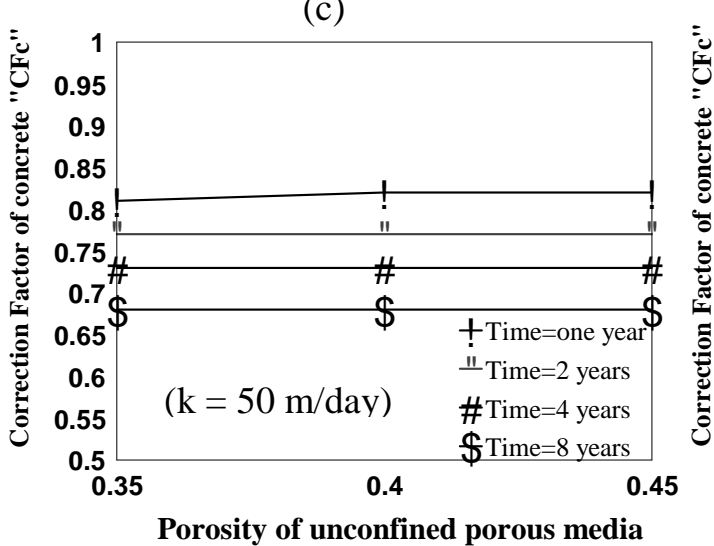

(b)

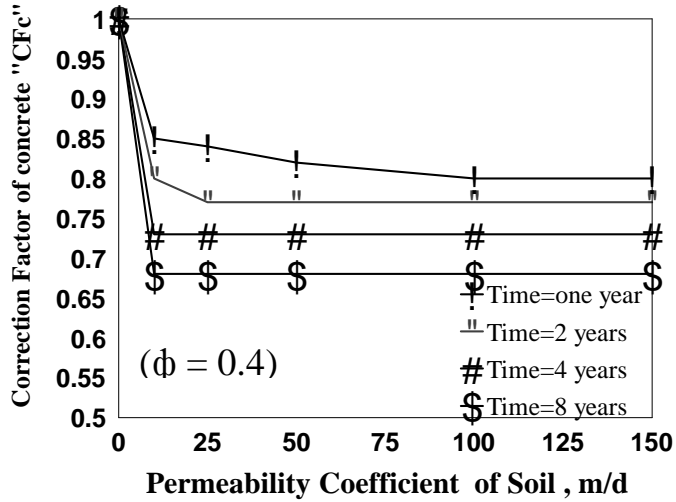

(d)

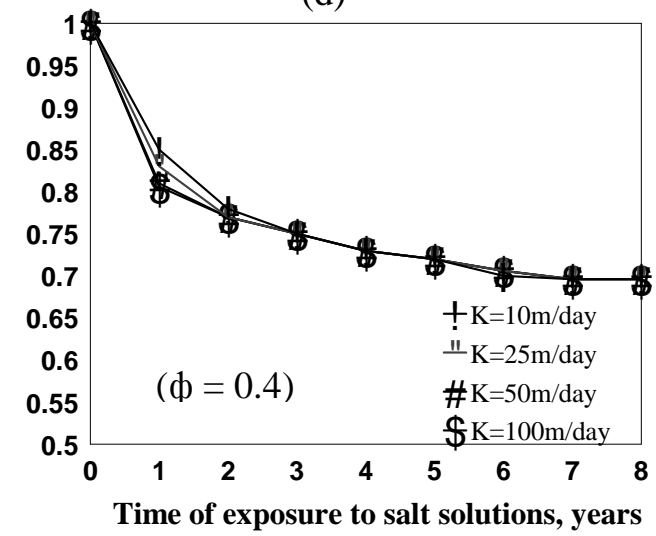

Fig. 8: Correction factor of future compressive strength " CFc " of R.C. columns in the chosen underground building versus porous media properties and time of exposure to sodium sulfate \&chloride salt solutions
a) "CFc " versus permeability coefficients at different times $(\phi=0.35)$,
b) " CFc " versus permeability coefficients at different times $(\phi=0.40)$,
c) "CFc " versus porosity of soil at different times ( $k=50 \mathrm{~m} / \mathrm{day})$, and
d) " CFc" versus time at different soil permeability coefficients $(\phi=0.4)$

Figures 9a, b show the future longitudinal strain of concrete " $\mathrm{Ec}_{\mathrm{f}}$ " of R.C. columns in the chosen building, damaged by the flow of suggested salt solutions, versus soil permeability at different times and for soil porosity $\phi=0.35 \& 0.40$ respectively. Obviously, " $\mathrm{Cc}_{\mathrm{f}}$ " is clearly affected by the corrosion rate of steel bars, which affected by the relative concentration of diffused salts and the porous media properties $(\mathrm{k}, \phi)$ until two years. As the soil permeability increases from $10 \mathrm{~m} / \mathrm{day}$ to $150 \mathrm{~m} /$ day, " $\mathrm{Ec}_{\mathrm{f}}$ " increases from $3.47 \times 10^{-4}$ to $3.64 \times 10^{-4}$ after one year and for soil porosity $=0.40$. After 2 years, " $\mathrm{Cc}_{\mathrm{f}}$ " increases from $3.92 \times 10-4$ to $3.96 \times 10-4$ by 
increasing soil permeability from 10 to $150 \mathrm{~m} /$ day. So, the effect of soil permeability decreases by increasing time of exposure of the chosen building to these salt solutions. But, as the soil porosity increases from 0.35 to 0.40 , " $\mathrm{Cc}_{\mathrm{f}}$ " slowly decreases from $3.47 \times 10^{-4}$ to $3.46 \times 10^{-4}$ after two years for soil permeability $\mathrm{k}=$ $50 \mathrm{~m} /$ day. So, the effect of soil permeability is greater than the soil porosity. It is necessary to notice that, the effect of soil properties is neglected after 2 years (as shown in Fig. 9c). From this figure it is clearly that the negligible effect of the soil porosity on the factor " $\mathrm{Ec} \mathrm{c}_{\mathrm{f}}$ " at the same permeability coefficient. This may be explained that, after 2 years the total relative concentration of the diffused salt solutions reaches the maximum value and becomes constant and equals the number of sewage water resources. This leads to the constant value of corrosion rate at that time and consequently constant values of concrete strain.

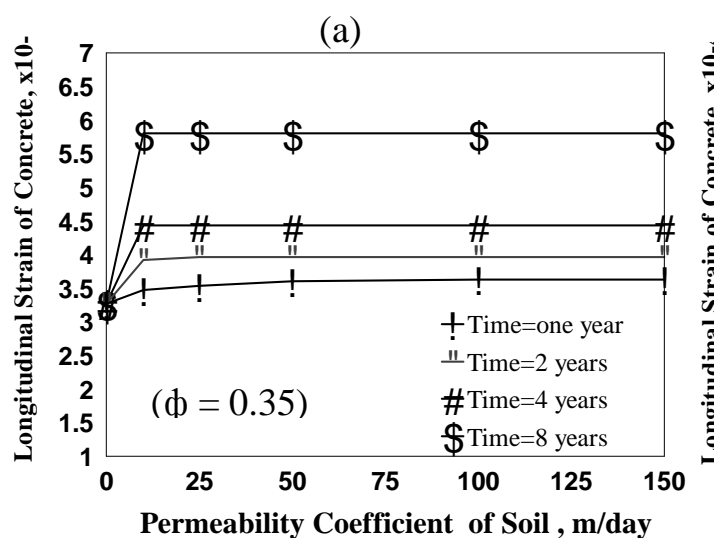

(c)

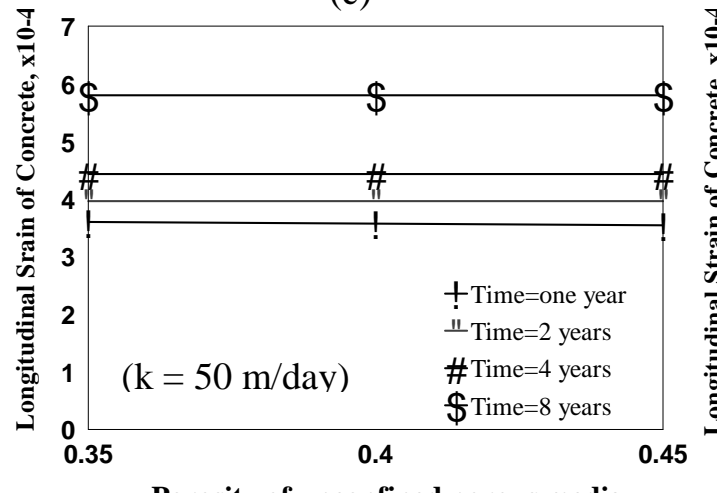

Porosity of unconfined porous media (b)

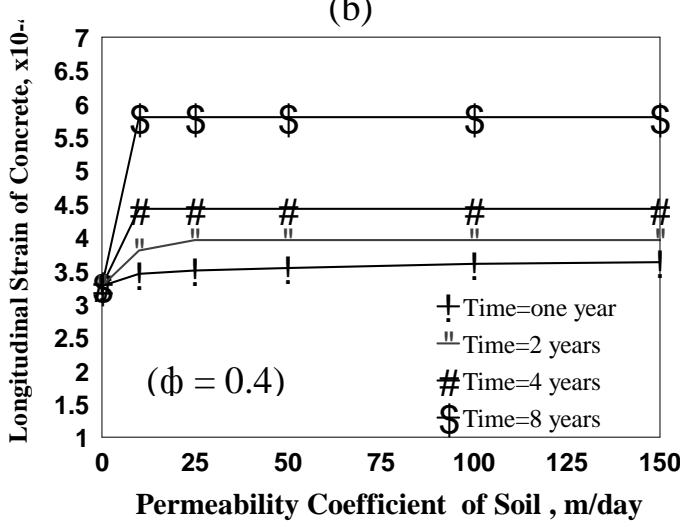

(d)

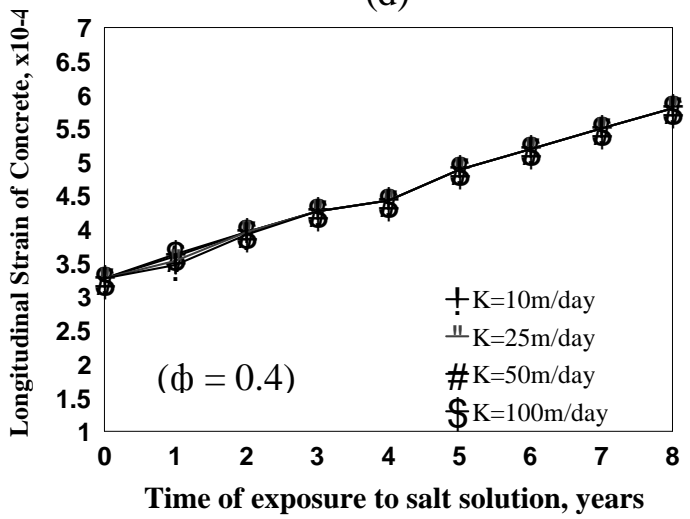

Fig. 9: Effect of unconfined porous media properties and time of exposure of the chosen underground building to sodium sulfate \&chloride salt solutions flow on the future longitudinal strain of concrete " $E c_{f}$ " of its R.C. columns
a) " $\Theta c_{f}$ " versus permeability coefficients at different times $(\phi=0.35)$,
b) " $\Theta c_{f}$ " versus permeability coefficients at different times $(\phi=0.45)$,
c) " $\epsilon c_{f}$ " versus porosity of soil at different times ( $k=50 \mathrm{~m} /$ day), and
d) " $E c_{f}$ " versus time at different soil permeability coefficients ( $\left.\phi=0.4\right)$ 
Figure 9d shows the relation between " $\mathrm{Cc}_{\mathrm{f}}$ " along period of time of building exposure to these salts at different permeability coefficients and for soil porosity $\phi=$ 0.40. Obviously, the effectiveness of the long time of exposure to these salt solutions on increasing " $\mathrm{Cc}_{\mathrm{f}}$ " of R.C. columns compared to the effect of porous media properties, which were neglected after 2 years. " $E c_{\mathrm{f}}$ " increased by about $20 \%$ (from 3.27 to $3.92 \times 10^{-4}$ ) after two years. But, after 8 years, " $E c_{\mathrm{f}}$ " increased by about $77 \%$ (from $3.27 \times 10^{-4}$ to $5.8 \times 10^{-4}$ ) for different values of soil properties compared to the same type of concrete (C250) not exposed to these salt solutions. This may be explained by the effect of the long time of exposure to these salts on generating corrosion rate and pitting corrosion of embedded reinforcement, internal cracks of concrete and deterioration of concrete cover due to sulfuric acids and chloride ions, which consequently increased deformations of the damaged concrete. $\square$

\section{4) Effect of confined and unconfined porous media on the deterioration of R.C. columns made from (NSC- C250) at the chosen underground building}

\section{4.a) Corrosion of embedded steel bars of the damaged R.C. columns}

\section{4.a.1) Expected Corrosion rate of embedded steel bars $\mathrm{Cr}(\mathrm{I}, \mathrm{J})$}

The same suggested previous data are used to determine the difference effect of confined and unconfined porous media of the same properties $(\mathrm{k}=100 \mathrm{~m} / \mathrm{day}, \Phi=$ 0.4 and $\mathrm{ds}=0.6 \mathrm{~mm})$ on the expected corrosion rate $\mathrm{Cr}(\mathrm{I}, \mathrm{J})$ of the embedded reinforcement in the R.C. columns damaged by the diffused salt solutions from five multiple sewage resources to the chosen building at point "A" taking the effect of time of exposure to these salts into consideration. The numerical results are computed and plotted in figure 10a. It is clear the effectiveness of the unconfined porous media on increasing corrosion rate of steel bars at any time compared to the confined of the same properties. After one year, expected corrosion rate of damaged bars reaches $2.7 \%$ for unconfined porous media and $1.15 \%$ for the confined. So, the unconfined porous media increases corrosion rate of steel bars by about $238 \%$ than the confined of the same properties after one year. Obviously, expected corrosion rate of damaged steel bars slowly increases with time for confined porous media until reaching the same value of corrosion (6.4\%) for the unconfined after 8 years of exposure of the chosen building to the suggested salt solutions. This is explained by the influence of the unconfined porous media on increasing the value of total relative concentration at the chosen building at any time than the confined.

\section{4.a.2) Reduction factor of future steel yield stress "CFs" of damaged columns}

The future yield stress "Fy" of embedded reinforcement can be determined, from the previous equation, depending on calculating a correction factor of steel yield stress "CFs" at any time level. The numerical results are computed, for the same suggested previous data of the chosen building and sewage resources, to determine the difference effect between confined and unconfined porous media of the same properties $(\mathrm{k}=100 \mathrm{~m} / \mathrm{day}, \Phi=0.4$ and $\mathrm{ds}=0.6 \mathrm{~mm})$ on the reduction factor of future 
yield stress $\mathrm{CFs}(\mathrm{I}, \mathrm{J})$ of the embedded reinforcement in the damaged R.C. columns taking the effect of time of exposure to these salts into consideration. The results are determined and plotted in figure $\mathbf{1 0 b}$.

(a)

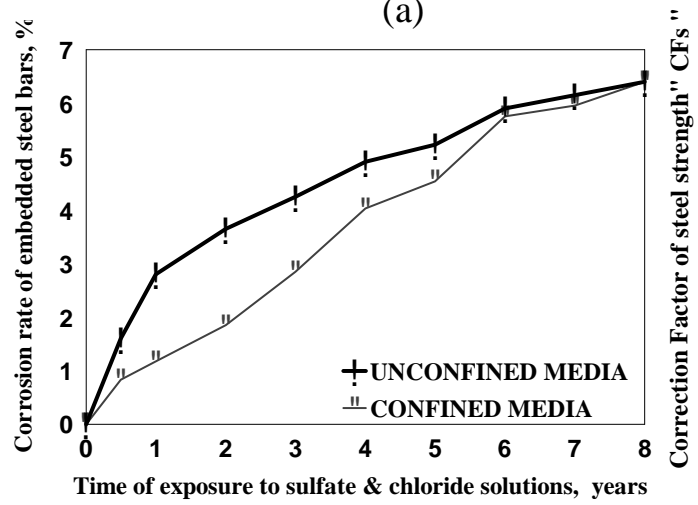

(b)

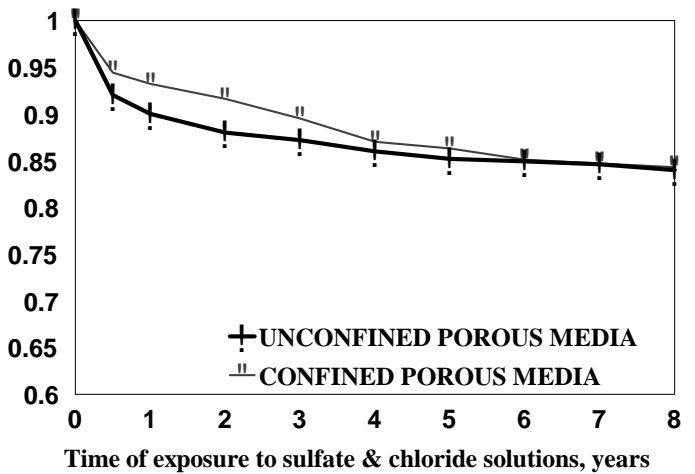

(c)

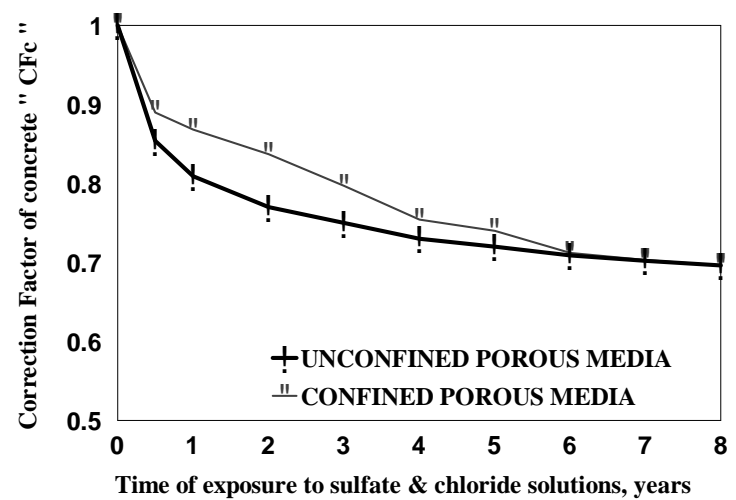

(d)

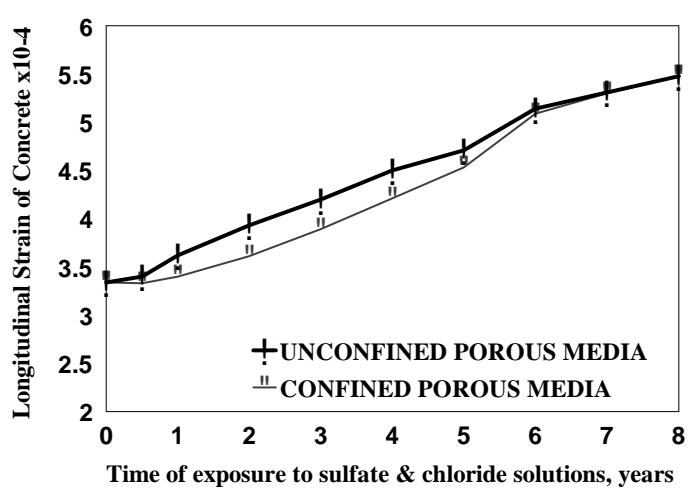

Fig. 10: Effect of confined and unconfined porous media on the mechanical properties losses of R.C. columns damaged by sodium sulfate and chloride salt solutions at the chosen building at point $(\mathrm{k}=100 \mathrm{~m} / \mathrm{day}, \Phi=0.4$ and $\mathrm{ds}=0.6 \mathrm{~mm})$.

a) corrosion rate of embedded reinforcement " $\mathrm{Cr}$ ' versus time(in years),

b) correction factor of steel yield stress "CFs" versus time(in years),

c) Correction factor of concrete compressive strength "CFc" versus time(in years),

d) Future longitudinal strain of concrete versus time (in years)

Obviously, the unconfined porous media has a clear effect on reducing the value of the correction factor of steel yield stress "CFs" at any time compared to the confined. The difference between the value of "CFs" for unconfined and confined porous media is small and its value depends largely on the time of exposure to the flow of the suggested salt solutions. After one year, "CFs" decreases by about $10.3 \%$ (from 1.0 to 0.897 ) for unconfined porous media, but, it decreases by about $6.6 \%$ (from 1.0 to 0.934 ) for the confined. After two years, "CFs" decreases by about $12 \%$ (from 1.0 to 0.88 ) for unconfined porous media, but, it decreases by about $8.4 \%$ (from 1.0 to 
0.916 ) for the confined. It is necessary to notice that, the value of "CFs" decreases as the time increases and the large decrease occurs with the unconfined porous media. But, the difference between the values of of "CFs" for unconfined and confined porous media decreases gradually and slowely with increasing time untill reaching equal value ("CFs" = 0.843) after 8 years. This explained by the effect of the unconfined porous media on increasing the amount of diffused salt solutions with time, to the chosen building, and consequently increasing corrosion, pitting \& longitudinal cracks of steel bars which decreases their stresses than the confined.

\section{4.b) Deterioration of concrete of R.C. columns in the chosen building}

\section{4.b.1) Reduction factor of future compressive strength "CFc" of concrete}

The future compressive strength of concrete " $\mathrm{Fc}_{\mathrm{f}}$ " for the damaged R.C. columns can be determined, from the previous equation, depending on calculating a correction factor of concrete compressive strength "CFc" at any time level. The numerical results are computed, for the same suggested previous data of the chosen building and sewage resources, to determine the difference effect between confined and unconfined porous media of the same properties $(\mathrm{k}=100 \mathrm{~m} / \mathrm{day}, \Phi=0.4$ and $\mathrm{ds}=$ $0.6 \mathrm{~mm})$ on the correction factor of future compressive strength $\mathrm{CFc}(\mathrm{I}, \mathrm{J})$ of normal strength concrete (NSC) in the damaged R.C. columns taking the effect of time of exposure to these salts into consideration. The results are determined and plotted in figure 10c.

Obviously, correction factor of concrete compressive strength "CFc" large decreases with increasing time than the correction factor of steel yield stress "CFs" for confined or unconfined porous media. The unconfined porous media has a clear and large effect on reducing the value of the correction factor of concrete strength "CFc" at any time compared to the confined of the same properties $(\mathrm{k}, \Phi, \mathrm{ds})$. The difference between the value of " $\mathrm{CFc}$ " for unconfined and confined porous media is noticeable and depends largely on the time of building exposure to the flow of the suggested salt solutions. After one year, "CFc" decreases by about 20\% (from 1.0 to 0.8 ) for unconfined porous media, but, it decreases by about $13 \%$ (from 1.0 to 0.87 ) for the confined. After two years, "CFc" decreases by about $23 \%$ (from 1.0 to 0.77 ) for unconfined porous media, but, it decreases by about $16 \%$ (from 1.0 to 0.84 ) for the confined. It is necessary to notice that, the value of " $\mathrm{CFc}$ " decreases as the time increases and the large decrease occurs with the unconfined porous media. But, the difference between the values of of "CFc" for unconfined and confined porous media decreases gradually and slowly with increasing time until reaching equal value ("CFc" = 0.696) after 8 years. This explained by the effect of the unconfined porous media on increasing the amount of diffused salt solutions with time, to the chosen building, and consequently increasing corrosion, pitting \& longitudinal cracks of concrete cover which decreases its compressive strength than the confined.

\section{4.b.2) Future longitudinal strain of concrete " $\epsilon c_{f}$ " of the damaged R.C. columns}

The future longitudinal strain of concrete " $\mathrm{Cc}_{\mathrm{f}}$ " for the damaged R.C. columns can be determined, from the previous equations, depending on calculating corrosion rate 
of steel bars and the initial value of strain before exposure to the suggested salt solutions at any time level. The numerical results are computed, for the same suggested previous data of the chosen building and sewage resources taking the effect of time of exposure to these salts into consideration. The results are determined and plotted in figure 10d. The unconfined porous media has a clear and large effect on increasing the value of the future longitudinal strain of concrete " $\mathrm{Cc}_{\mathrm{f}}$ " at any time compared to the confined of the same properties $(\mathrm{k}, \Phi, \mathrm{ds})$. The difference between the value of " $\mathrm{Cc}_{\mathrm{f}}$ " for unconfined and confined porous media is noticeable and depends largely on the time of building exposure to the flow of the suggested salt solutions. After one year, " $\mathrm{E} \mathrm{c}_{\mathrm{f}}$ " increases by about $11 \%$ (from $3.27 \times 10^{-4}$ to $3.63 \times 10^{-4}$ ) for unconfined porous media, but, it increases by about $4.3 \%$ (from $3.27 \times 10^{-4}$ to $3.41 \times 10^{-4}$ ) for the confined. After two years, " $\mathrm{Cc}_{\mathrm{f}}$ " increases by about $20 \%$ (from $3.27 \times 10^{-4}$ to $3.93 \times 10^{-4}$ ) for unconfined porous media, but, it decreases by about $10 \%$ (from $3.27 \times 10^{-4}$ to $3.61 \times 10^{-4}$ ) for the confined. It is necessary to notice that, the value of " $E c_{\mathrm{f}}$ " increases as the time increases and the large increase (about two times) occurs with the unconfined porous media. But, the difference between the values of of future longitudinal strain of concrete of R.C. columns for unconfined and confined porous media is bigger in the first years of exposure to these salt solutions. But, this difference decreases gradually and slowly with increasing time until reaching the same value of strain (" $E \mathrm{c}_{\mathrm{f}}$ " $\left.=5.48 \times 10^{-4}\right)$ for the case of confined and unconfined porous media after 8 years. This explained by the effect of the unconfined porous media on increasing the amount of diffused salt solutions with time, to the chosen building, and consequently increasing corrosion of steel, pitting corrosion, internal cracks of concrete, amount of macro pores and longitudinal cracks of concrete cover which increases the deformation of concrete than the confined.

\section{CONCLUSIONS}

The main conclusions about the prediction of the mechanical properties losses of the damaged R.C. columns by sodium sulfate and chloride solutions induced by multiple sewage water resources, penetrating an unconfined porous media, may be summarized as follows:

1. Theoretical equations and a computer program were developed, depending on experimental data, for predicting the mechanical properties losses of underground R.C. elements damaged by induced sewage water through unconfined porous media after any service time of the building.

2. The total relative concentration of the diffused salts $" \mathrm{C}_{\mathrm{A}} / \mathrm{C}_{\mathrm{o}} "$ at the chosen underground building increases gradually and rapidly with the time approaching the unity or number of sewage resources depending mainly on the time, soil properties, recharge value of each sewage resource and radial distance from the chosen building to them. $" \mathrm{C}_{\mathrm{A}} / \mathrm{C}_{\mathrm{o}}$ " at the chosen building reaches the number of sewage resources at time equals two years. After two years, the soil properties have no any influence on the total relative concentration of diffused salts.

3. Future corrosion rate of embedded steel bars of the R.C. columns in the chosen building is clearly affected by the total relative concentration of salt solutions " $\mathrm{C}_{\mathrm{A}} / \mathrm{C}_{\mathrm{o}}$ ", time of exposure to these salts " $\mathrm{t}$ ", and properties of the unconfined 
porous media until 2 years. After 2 years, the effect of soil permeability is neglected and the time of exposure to these salts has a main effect on increasing corrosion damage of steel bars. Corrosion rate of embedded steel bars in R.C. columns will be equal to $6.8 \%$ after 8 years for the proposed data of the problem in this research.

4. Reduction factor of future steel yield stress "CFs "in the R.C. columns damaged by the flow of the suggested salt solutions is weakly affected by the unconfined porous media properties $(\mathrm{k}, \phi)$ until two years and the clearly effect occurs with soil permeability. After 2 years , "CFs " reaches $12 \%$ for different values of soil properties compared to the same type of concrete not exposed to these salts. The soil porosity has a neglected effect on this factor at any time .

5. Reduction factor of future compressive strength of concrete " $\mathrm{CFc}$ " of R.C. columns in the chosen building, damaged by the flow of suggested salt solutions, is clearly affected by the corrosion rate of steel bars, which affected by the relative concentration of diffused salts and the porous media properties $(\mathrm{k}, \phi)$ until two years. After 2 years, " $\mathrm{CFc}$ " reaches to $23 \%$ for different values of soil properties compared to the same type of concrete not exposed to these salts .The effect of soil properties on this factor is neglected after 2 years.

6. The effectiveness of the long time of exposure to these salt solutions on decreasing the values of "CFs" and" $\mathrm{CFc}$ " compared to the effect of porous media properties, which was neglected after 2 years. After 8 years, "CFs \& CFc " will be equal to $16 \% \& 31.4 \%$ respectively for different values of soil properties compared to the same type of concrete (C250) not exposed to these salts.

7. The future longitudinal strain of concrete " $\mathrm{Ec} c_{f}$ "of R.C. columns in the chosen building, damaged by the flow of suggested salt solutions is clearly increased by the corrosion rate of steel bars, the relative concentration of diffused salts and affected by the porous media properties $(\mathrm{k}, \phi)$ until two years. The effect of soil permeability decreases by increasing time of exposure of the chosen building to these salt solutions. But, the soil porosity has a neglected influence on this factor.

8. The long time of building exposure to these salt solutions has the main effect on increasing " $\mathrm{Ec}_{\mathrm{f}}$ " of R.C. columns compared to the effect of porous media properties, which are neglected after 2 years. " $\mathrm{Cc}_{\mathrm{f}}$ " increases by about $20 \%$ after two years. But, after 8 years, " $E c_{\mathrm{f}}$ " increases by about $77 \%$ for different values of soil properties compared to the same type of concrete (C250) not exposed to these salt solutions.

9. The unconfined porous media has a clear and large effect on reducing the value of the correction factor of concrete strength " $\mathrm{CFc}$ " and increasing the value of the future longitudinal strain of concrete " $\mathrm{Cc}_{\mathrm{f}}$ " at any time compared to the confined of the same properties $(\mathrm{k}, \Phi, \mathrm{ds})$. The difference between the values of of " $\mathrm{CFc}$ " and " $\mathrm{Cc}_{\mathrm{f}}$ " for unconfined and confined porous media decreases gradually and slowly with increasing time until reaching equal value ("CFc" = $0.696, " \mathrm{Cc}_{\mathrm{f}}$ " $=5.48 \times 10^{-4}$ ) after 8 years. 


\section{REFERENCES}

[1] Hughes , D. C. , "Sulfate Resistance of OPC/Fly Ash and SRPC Pastes : Pore Structure and Permeability ", Cement and Concrete Research , Vol. 15 , No. 6 , pp. 1003- 1012,1985 .

[2] Negro and Mario Collepardi ,"Sulfate attack of concrete building foundations induced by sewage waters ", Cement and Concrete Research, Vol. 32 , ISSUE 6, June 2002, pp. 843-849.

[3] Rashwan, M. M. and Sadeek, R. A .,"Mechanical behavior of R. C. columns damaged by corrosion of reinforcement ", Bulletin of the Faculty of Eng. , Assiut Univ. , Assiut, Vol. 25 , pp. 37-44, July , 1997.

[4] N.I. Fattuhi and B.P. Hughes, " Effect of acid attack on concrete with different admixtures or protective coatings", Cem. Concr. Res.13, 1983, pp.655- 665 .

[5] K. Torii and M. Kawamura, " Effect of fly ash and silica fume on the resistance of mortar to sulfuric acid and sulfate attack", Cem. Concr. Res.242, 1994, pp. $361-370$.

[6] P. K. Mehta, " Sulfate attack on concrete - a critical review " In : Materials Science of Concrete III, American Ceramic Society, Westerville, OH, 1993, PP. $105-130$.

[7] Manu Santhanam, Menashi D. Cohen and Jan Olek, " Mechanism of sulfate attack : A Fresh Look", Cement and Concrete Research, Vol. 32 , ISSUE 6, June 2002, pp. 915 - 921.

[8] Adam Neville, " The confused world of sulfate attack on concrete", Cement and Concrete Research, Vol. 34 , ISSUE 8, August 2004, pp. 1275- 1296.

[9] Hoopes, J. A. and Harleman, D. R. F. ,"Waste water recharge and dispersion in porous media " , Jour. of Hyd. Div. , ASCE, Vol. 93 No. 5 , 1967.

[10] Theis , C. V. , "The relation between the lowering of the piezometric surface and the rate of duration of discharge of a well using ground water storage ", Trans. , Amer. Geophs. , Union ,Vol. 16, pp. 519-524, 1935.

[11] Day, P. R. ," Dispersion of a moving salt-water boundary advancing through a saturated sand ", Trans ., Am. Geophys. Union, 37, pp. 595-601, 1965.

[12] Abdelsadek , F. I. , "The solution of the problem of salt migration in soil" , Bulletin of the Faculty of Eng., Assiut Univ. , Vol. 5 , No. 1, Jan., 1977.

[13] Rashwan, M. M., Abdelsadek , F. I. , Gamal ,A. Megahid, and Ali, N.A., "Study of waste water disposal through seepage pits", A Thesis of Master of Science, Department of Civil Engineering , Assiut University, Assiut, Egypt, 1989, pp. $1-242$.

[14] Ali , N. A. and Rashwan , M. M. , "Analytic model for dispersion of recharged waste-waters through multiple wells in porous media ", Int. Conf. of Water Technology , Alexandria-Egypt , pp. 473-485, March , 1997.

[15] De Josselin , J. G. , " Longitudinal and transverse diffusion in granular deposits" , Trans. , Am. Geophys. Union, 39, pp. 67-74, 1958.

[16] Yih , C. G. , "Flow of a non-homogeneous fluid in porous media " , Jour. of Fluid Mech. , Vol. 10 , pp. 133-140, 1960 .

[17] Rashwan, M. M., " A Numerical study for the effect of salt solutions dispersion in a porous media on the load carrying capacity of underground R.C. columns" 
Journal of Engineering Sciences -JES, Vol. 33, No. 1, January 2005, pp.103 120 .

[18] El-Kassaby E.A., Hashem M.M., Mohamed R.A.S., and Ragab E.M.H.,'The resistance of dolomite concrete exposed to chemical attack", Journal of Engineering Sciences -JES, Vol. 33, No. 3, May 2005, pp.721 - 733 .

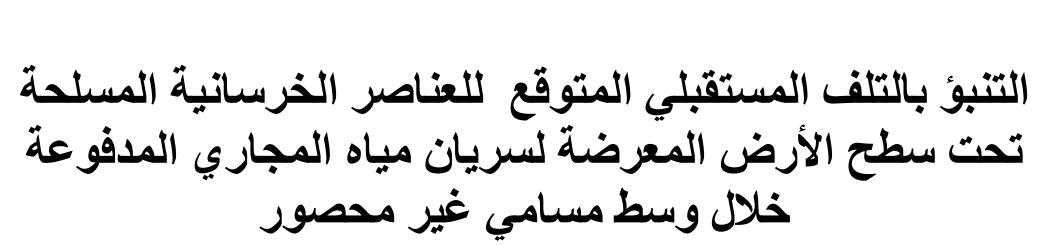

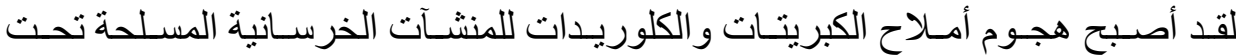

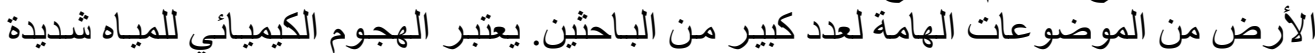

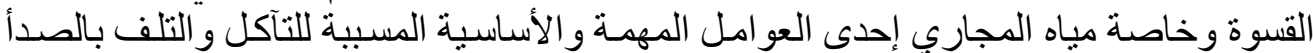

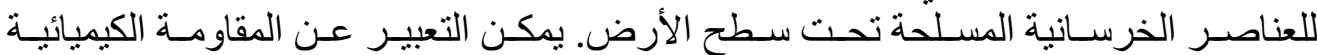

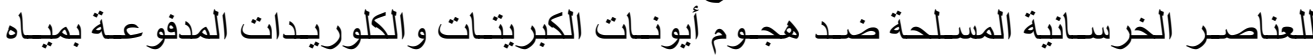

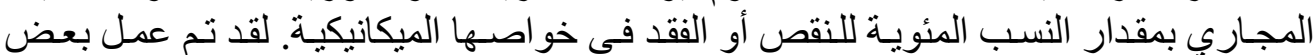

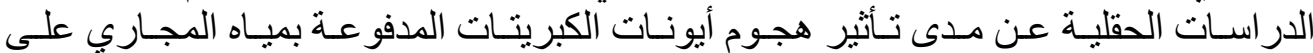

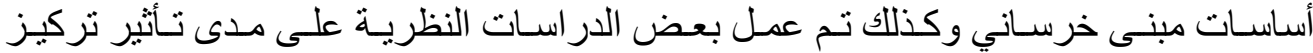

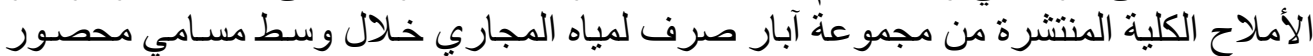

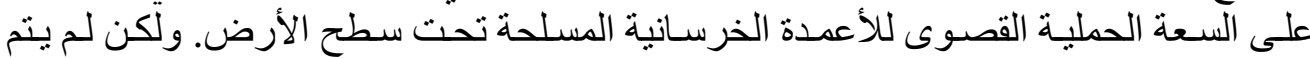

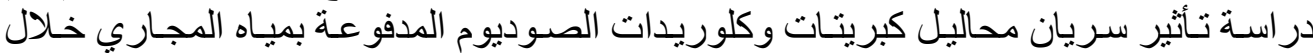

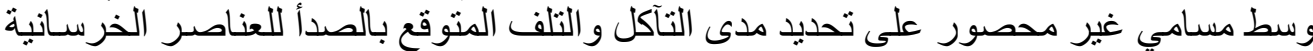

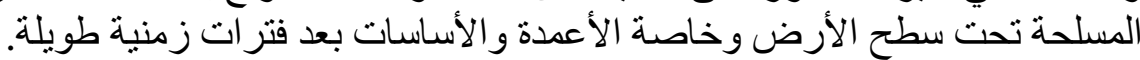

لذللك فإن الغرض الرئيسي من هذا البحث هو تطوير البرنـامج النظري المبني على بعض

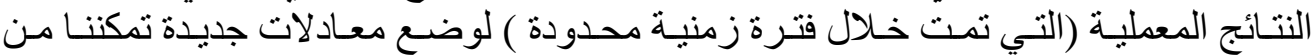

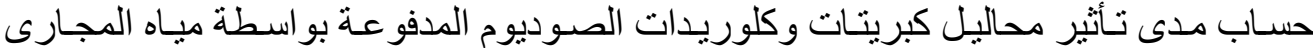

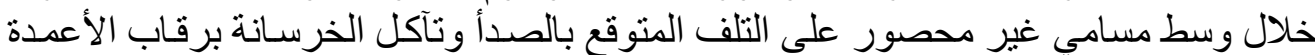

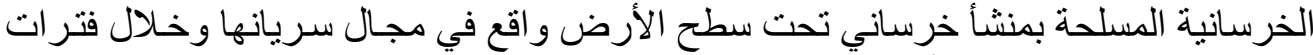

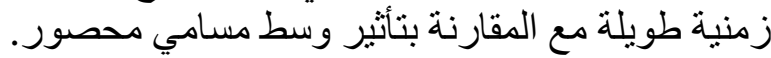

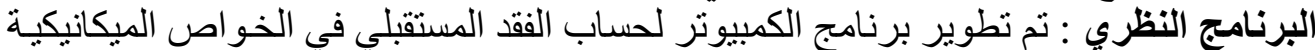

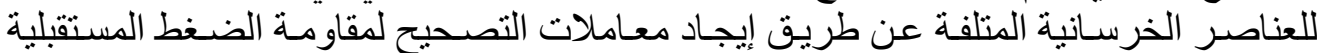

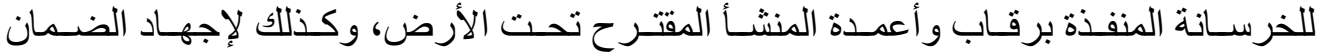

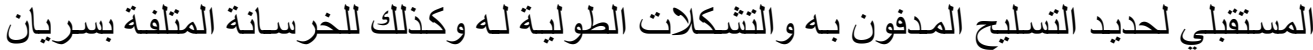

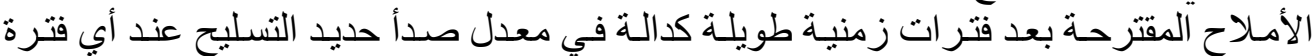

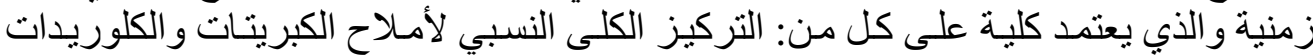

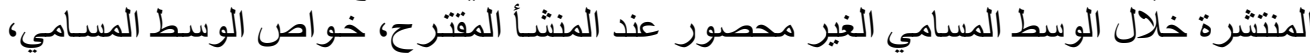

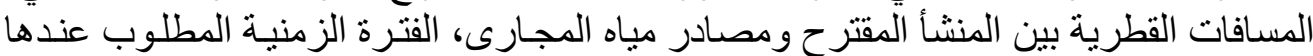


حسـاب الفقد المستقبلي في الخواص الميكانيكية للعناصر الخرسـانية وتم حل هذه المعـادلات بطريقة الفروق العددية المحددة .

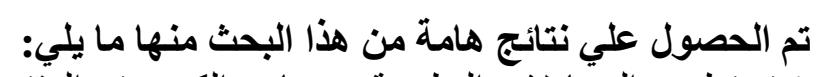

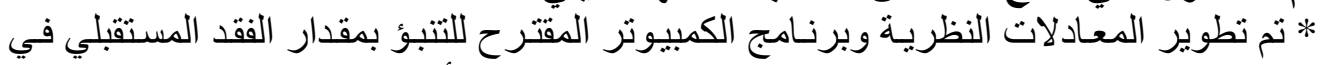

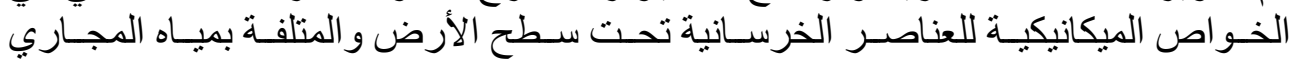

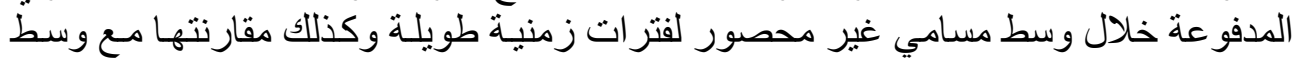
مسامي محصور خلارل * أوضحت نتائج التحليل العددي أن التآكل و التلف المتوقع بالصدأ لأي عنصـر من العناصـر

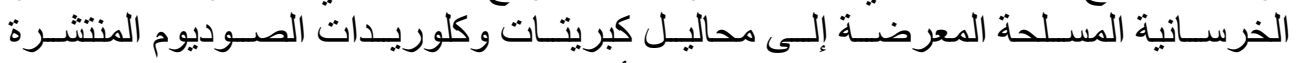

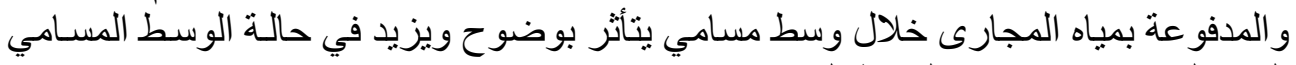

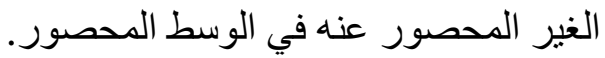

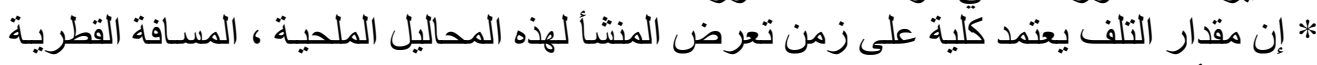

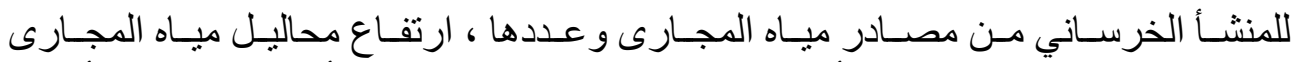

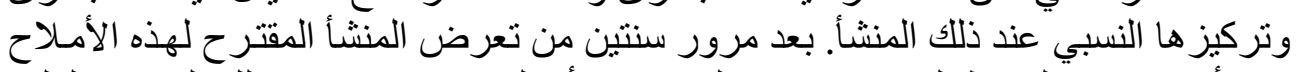

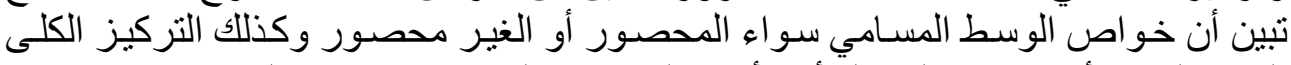

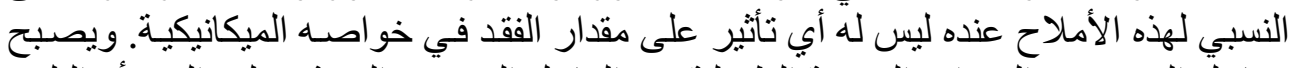

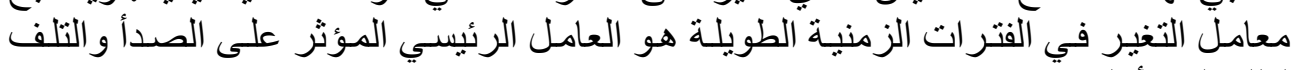
لذلك المنشأ الخرساني. 